\title{
Just culture en herstelrecht in de afwikkeling van medische schade
}

\author{
$M r . B . S . L a a r m a n^{*}$
}

\section{Introductie}

Het aansprakelijkheidsrecht wordt beheerst door een pijnlijke paradox. Velen zijn het inmiddels met elkaar eens dat het primaire doel van het aansprakelijkheidsrecht herstel zou moeten zijn, maar de juridische wegen die schadelijdende patiënten inslaan om tot herstel te komen zijn in de regel belastend. Die belasting kan zodanig zijn dat procedures vaker meer dan minder schade tot gevolg hebben, een fenomeen dat in wetenschappelijke literatuur 'secundaire victimisatie' wordt genoemd. ${ }^{1}$ Daarom bestaat de afgelopen jaren veel aandacht voor het belang van openheid in de zorg. ${ }^{2}$ Snel openheid geven

\footnotetext{
Mr. B.S. Laarman is docent-onderzoeker aan het Amsterdam Centre for Comprehensive Law (ACCL), verbonden aan de afdeling Privaatrecht van de Faculteit Rechtsgeleerdheid van de Vrije Universiteit, en de uitvoerend onderzoeker in project OPEN.

Dit artikel is gebaseerd op onderzoek dat door de auteur in samenwerking met anderen is verricht in het kader van het Leernetwerk OPEN OPEN is een leernetwerk van ziekenhuizen en onderzoekers van de VU (prof. mr. Arno Akkermans en mr. Berber Laarman), het Nivel (prof. dr. ir. Roland Friele en dr. Renée Bouwman) en Amsterdam UMC/UvA (prof. mr. Johan Legemaate). In OPEN worden inzichten opgedaan over de organisatie van openheid na medische incidenten (www.openindezorg.nl). OPEN is van 2015 tot 2019 gefinancierd door Fonds Slachtofferhulp. Ik wil prof. mr. Arno Akkermans (Vrije Universiteit), prof. Dick Allewijn (Vrije Universiteit), dr. Nieke Elbers (NSCR), drs. Iris Beckx (NSCR) en mr. Geertruid van Wassenaer (Van Wassenaer Wytema Advocaten) heel hartelijk danken voor hun opmerkingen bij conceptversies van deze bijdrage.

1. Zie o.m. A.J. Akkermans \& K.A.P.C. van Wees, Het letselschadeproces in therapeutisch perspectief: hoe door verwaarlozing van zijn emotionele dimensie het afwikkelingsproces van letselschade tekortschiet in het nastreven van de eigen doeleinden, TVP 2007, afl. 4, p. 103-118, en recenter A.J. Akkermans, Think rehab! Over de prioriteit van herstel, herstelgerichte dienstverlening, de knikkers en het spel, in: (Je) geld of je leven (terug). Vergoeding in natura. Voordrachten gehouden op het symposion van de Vereniging van Letselschade Advocaten 2015, p. 11-36 en S.D. Lindenbergh, Herstel bij letsel. Over de juridische fundering van verplichtingen in herstel, in: Kritiek op recht. Liber amicorum Gerrit van Maanen, Deventer: Kluwer 2014, p. 239-252, gevonden op http://hdl.handle.net/1765/76122.

2. Openheid is sinds 2016 een wettelijke plicht, neergelegd in art. 10 lid 3 Wkkgz. Openheid is een van de aanbevelingen van de Gedragscode Openheid na medische incidenten; betere afwikkeling Medische Aansprakelijkheid (GOMA) 2010, evenals van de recent herziene KNMG Richtlijn 'Omgaan met incidenten en klachten: wat wordt van artsen verwacht?' In Leernetwerk OPEN worden inzichten opgedaan hoe openheid het beste aangepakt kan worden. Op www.openindezorg.nl is een groot aantal publicaties vrij te downloaden omtrent het belang en de organisatie van openheid, waaronder het recent verschenen onderzoeksverslag over de jaren 2015-2018: B.S. Laarman, A.J. Akkermans, J. Legemaate, R. Bouwman \& R.D. Friele, Ervaringen met de organisatie van een OPEN beleid in Nederlandse ziekenhuizen. Verslag en resultaten
} van handelingsonderzoek, Utrecht: Nivel 2018. na een incident kan secundaire victimisatie in bepaalde gevallen voorkomen, omdat daarmee de noodzaak tot klagen of claimen in ieder geval deels wordt weggenomen. Patiënten die klagen of claimen, doen dat namelijk vaak omdat zij het om uiteenlopende redenen niet voor elkaar kregen een open gesprek met hun zorgverlener te voeren. ${ }^{3}$

Open en eerlijk zijn lijkt vanzelfsprekend, maar dat is het niet. Behalve de patiënt kunnen ook zorgverleners lijden onder een gebeurtenis, zeker wanneer daarop juridische procedures volgen. Dat geldt met name wanneer er sprake is van 'blame culture', een cultuur waar met verwijten en sancties wordt gereageerd wanneer er iets misgaat. Om open en eerlijk naar patiënten en naar elkaar te kunnen zijn, moeten zorgverleners zich juist veilig voelen om zich over onveilige situaties of incidenten uit te spreken. Daarom wordt in de gezondheidszorg gezocht naar manieren om de omslag te maken van een gesloten en hiërarchische 'blame culture', naar een open 'just culture.' ${ }^{4}$

Wie openheid als een adequaat proces inricht, kan daarmee nodeloze claims voorkomen, maar met het enkele geven van openheid is bovengenoemde pijnlijke paradox nog niet opgelost. Openheid is namelijk niet instrumenteel, of zou dat niet moeten zijn, in het voorkomen van claims. Patiënten die schade lijden door medisch handelen moeten inderdaad open tegemoet worden getreden, maar daarnaast natuurlijk ook hun schade fatsoenlijk vergoed kunnen krijgen zonder dat dat hen zieker maakt. Ook in het recht wordt nagedacht over manieren om te voorkomen dat procedures schade veroorzaken. Dat heeft geresulteerd in verschillende denkrichtingen, waarin bijvoorbeeld de rol van de rechter, de taakopvatting van de belangenbehartiger, de inrichting van het proces of de te vergoeden schade op alternatieve manieren wordt benaderd. Eén van die benaderingen is 'restorative justice', in het Nederlands beter

3. C. Vincent, M. Young \& A. Phillips, Why do people sue doctors? A study of patients and relatives taking legal action, The Lancet 1994, p. 1609-1613, op p. 1612, en J. Legemaate, Het klachtrecht van de patiënt, TvGR 2007, afl. 6, p. 418-427, op p. 420-421.

4. De Inspectie stuurt sinds enige jaren aan op just culture: E. Nyst, Just culture in toekomstvisie IGZ, Medisch Contact 12 oktober 2015; in ziekenhuizen wordt bijv. getraind op aanspreekgedrag in medisch teamwork, zie B.S. Laarman, M.C. Bomhoff, R. Friele, A.J. Akkermans \& J. Legemaate, OPEN schriftelijke rapportage van het eerste jaar OPEN. Utrecht: Nivel 2016, p. 48. Ook het Veilig Incidenten Melden kan als onderdeel worden gezien van just culture. 
bekend als 'herstelrecht'. Herstelrecht, heel kort gezegd, is het idee dat recht moet verbinden in plaats van polariseren, en dat het daarom belangrijk is om de betrokkenen bij schadeveroorzaking samen naar oplossingen te laten zoeken.

Sydney Dekker, bekend om zijn werk over menselijke fouten en veiligheid in hoogrisico-industrieën zoals de luchtvaart en de gezondheidszorg, legt aan zijn definitie van just culture de beginselen van herstelrecht ten grondslag. Kan zijn definitie van 'restorative just culture' behulpzaam zijn in het nadenken over de afwikkeling van medische schade? In deze bijdrage wordt onderzocht wat er vanuit een restorative of, in het Nederlands, 'herstelgericht' perspectief te zeggen is over de afwikkeling van medische schade. Biedt restorative just culture anknopingspunten voor een afwikkeling van medische schade die beter aansluit bij de behoeften van betrokkenen?

Ter beantwoording van deze vraag wordt aangevangen met een introductie in het patiëntveiligheidsdiscours door kort in te gaan op het fenomeen 'blame culture' (par. 3), de impact van een incident op zorgverleners (par. 4) en de opkomst van 'just culture' (par. 5). Juristen komen op bekender terrein wanneer de stap wordt gezet naar de afwikkeling van medische klachten en claims (par. 6), maar we blijven nog even in het psychosociale domein met een bespreking van de negatieve impact daarvan in de gezondheidszorg. Het herstelrecht staat niet op zichzelf, maar is onderdeel van een bredere ontwikkeling in het recht. Daarom wordt eerst de blik verbreed naar de verschillende innovatieve opvattingen van recht en rechtstoepassing die wel zijn samengebracht onder de noemer 'The Comprehensive Law Movement' (par. 7). Daarna keert de focus terug naar het herstelrecht. Eerst wordt een omschrijving gegeven van wat herstelrecht inhoudt (par. 8), daarna volgt een bespreking van ervaringen met herstelrecht in het strafrecht (par. 9), waarna de mogelijke meerwaarde van een herstelgerichte aanpak in het waarborgen van een open en eerlijke reactie na een incident in de gezondheidszorg volgt, ook wanneer het gaat om de vergoeding van schade (par. 10). In paragraaf $11 \mathrm{mag}$ het tegengeluid niet ontbreken, waarna in de conclusie (par. 12) een bevestigend antwoord wordt gegeven op de hoofdvraag.

\section{Praktische opmerkingen vooraf}

Deze bijdrage legt een verband tussen just culture en schadeafwikkeling. Just culture is ontstaan vanuit de behoefte zorgverleners een veilige leeromgeving te bieden en vertrekt daarom logischerwijs vanuit het perspectief van de zorgverlener. Het is hierom dat ik eerst de impact van conflictueuze schadeafwikkeling op de zorgverlener bespreek, om daarna duidelijk te maken dat just culture zich ook uitstrekt tot de patiënt, en dat daarom ook de afwikkeling van schade 'just' moet gebeuren. Hier zij benadrukt dat deze volgorde niet betekent dat aan de belangen van de zorgverlener meer waarde wordt toegekend dan aan die van de patiënt. Immers, zelfs als just culture op het eerste gezicht vooral de zorgverlener ten goede komt, is dat vaak nog steeds in het voordeel van de patiënt. Daarover later meer.

In Nederland kennen we herstelrecht in strafrechtelijke context. Dat betekent dat in studies naar toepassing en effect van herstelrecht over 'daders' en 'slachtoffers' wordt gesproken. In deze bijdrage wordt het gebruik van deze aanduidingen zo veel mogelijk vermeden, omdat ze in medische context ongepast en mogelijk grievend zijn. Wanneer wel over daders of slachtoffers wordt gesproken, is dat of tussen aanhalingstekens om duidelijk te maken dat daarmee niet wordt bedoeld dat de zorgverlener als dader wordt gezien, of in uitsluitend strafrechtelijke context. ${ }^{5}$

In deze bijdrage wordt gesproken over de zorgaanbieder en de zorgverlener. Met de zorgaanbieder wordt gedoeld op de instelling, met de zorgverlener wordt de individuele professional bedoeld. De Wet kwaliteit klachten en geschillen zorg (Wkkgz) verstaat onder 'zorgaanbieder' alle zorgaanbieders, niet alleen de 'cure', maar ook de 'care', zowel instellingen als solistisch werkende zorgverleners, waaronder de geestelijke gezondheidszorg (GGZ), de verpleging, verzorging en thuiszorg (de VVT-sector) en de eerste lijn zoals de huisartsenzorg. ${ }^{6}$ In sommige gevallen vallen de begrippen zorgaanbieder en zorgverlener dus samen in één persoon, terwijl de verantwoordelijkheden die zorgaanbieders in sommige gevallen worden toegedicht (bijvoorbeeld in de afwikkeling van schade) niet zonder meer bij een individuele zorgverlener kunnen worden gelegd. Het is daarom onvermijdelijk dat het hier besprokene niet voor al deze zorgaanbieders kan opgaan. ${ }^{7}$ Waar nodig wordt hier nadrukkelijk op gewezen.

\section{Blame-cultuur}

Een blame-cultuur is een cultuur waarin op incidenten wordt gereageerd met verwijten en sancties. Een voorbeeld van blame-cultuur dat iedereen zal herkennen, is de manier waarop 'medische missers' in het nieuws worden gebracht. Denk verder aan het openbaar maken van aantallen calamiteitenmeldingen per zorginstelling, ${ }^{8}$ het met naam en toenaam publiceren van zorgverleners die een tuchtmaatregel kregen opgelegd, sinds april 2019 overigens weer beperkt tot de beroepsbeper-

5. Overigens is het gebruik van 'dader' en 'slachtoffer' ook in het strafrecht ter discussie gesteld. In die zin W.J. Veraart, Bescherm het slachtoffer, begin bij de verdachte, Justitiële verkenningen (41) 2015, afl. 5, p. 62-80. 6. Art. 1 Wkkgz.

7. Daarom heeft het Nivel samen met huisartsenposten een parallel OPEN-leernetwerk opgezet dat inzicht opdoet over openheid na klachten en incidenten in de huisartsenzorg: www.nivel.nl/nl/nieuws/startproject-open-de-huisartsenzorg-over-omgaan-met-incidenten-dehuisartsenzorg.

8. RTL Nieuws, Zoveel medische fouten makten ziekenhuizen in jouw buurt, 27 maart 2018, www.rtlnieuws.nl/nieuws/nederland/artikel/ 4127656/zoveel-medische-fouten-maakten-ziekenhuizen-jouw-buurt, laatst bezocht op 26 september 2018. 
kende maatregelen," of, zoals zich vorig jaar nog in het Verenigd Koninkrijk afspeelde, ${ }^{10}$ strafrechtelijke vervolging van zorgverleners die bij een incident betrokken zijn - met alle media-aandacht die daarbij hoort. ${ }^{11}$ De kern van een blamecultuur is het reageren op tekortschieten met verwijt en straf. Blame is niet altijd bewust, maar kan ook onbedoeld een procedure binnensluipen, bijvoorbeeld tijdens het horen van een zorgverlener in het kader van een calamiteitenonderzoek. $^{12}$

Een blame-cultuur is funest voor de kwaliteit van zorg. Dat is ten eerste zo omdat er uit angst voor negatieve consequenties minder snel met leidinggevenden, elkaar of de patiënt over incidenten gesproken wordt. ${ }^{13}$ Een blame-cultuur staat ook onderlinge kritiek in de weg. Uit onderzoek blijkt dat zorgverleners elkaar sowieso al niet vaak aanspreken op onveilig of ongewenst gedrag ${ }^{14}$ en daar in een blame-cultuur ook minder snel melding van maken bij een leidinggevende. ${ }^{15}$ Ook is bekend dat coassistenten of artsen in opleiding hun opleidend arts of leidinggevende niet snel durven bekritiseren, omdat zij bang zijn hun toekomstige carrière in gevaar te brengen. ${ }^{16} \mathrm{Tot}$

9. De tuchtrechter zal een berisping alleen nog openbaar maken wanneer daar aanleiding toe is. Kamerstukken II 2017/18, Wijziging van de Wet op de beroepen in de individuele gezondheidszorg in verband met de verbeteringen die worden doorgevoerd in het tuchtrecht alsmede verbetering ten aanzien van het functioneren van de wet, 34629 , amendement van het lid van den Berg. Zie ook O. Nunes \& C. de Haan, Wijziging in het medisch tuchtrecht in de nieuwe Wet BIG, L\&S 2019, afl. 2, p. 5-16.

10. Zie o.m. het British Medical Journal, dat kopte met 'Back to blame?', www.bmj.com/bawa-garba, laatst geraadpleegd op 12 februari 2018.

11. Strafrechtelijke vervolging van zorgverleners komt in Nederland maar zelden voor, maar kan grote gevolgen hebben voor alle betrokkenen. Wat dat betreft liggen de gebeurtenissen omtrent de vervolging van huisarts Tromp uit Tuitjenhorn sommigen waarschijnlijk nog vers in het geheugen.

12. A. Wu, Medical error, incident investigation and the second victim. Doing better but feeling worse? BMJ Quality \& Safety (21) 2012, afl. 4 , p. 267-270; C. Craun Ferguson, The emotional fallout from the culture of blame and shame, Journal of the American Medical Association (JAMA) Pediatrics 2017/171, afl. 12, p. 1141. Zie hierover L.E. Hirschinger e.a., The natural history of recovery for the healthcare provider 'second victim' after adverse patient events, BMJ Quality \& Safety Edition 2009, afl. 18, p. 325-330, die op p. 328 'enduring the inquisition' de fase waarin de instelling reageert op de gebeurtenis, als belastende fase in het herstel van second victims benoemen.

13. L.C. Kaldjian, E.W. Jones \& G.E. Rosenthal, Facilitating and impeding factors for physicians' error disclosure. A structured literature review, The Joint Commission Journal on Quality and Patient Safety (32) 2006, afl. 4, p. 188-198.

14. J.W. Weenink \& T. Kool, Sturen op verantwoord functioneren en omgaan met verminderd functioneren van zorgverleners, Scientific Center for Quality of Healthcare (IQ healthcare), Radboud UMC, 2016.

15. Onderzoek van Heuver en Bomhoff naar cultuur in ziekenhuizen wees uit dat medewerkers elkaar vaak zien als familie: 'Dat familiegevoel schuurde echter met de zogenaamd neutraal gepresenteerde meldprocedure, want: "de ander verlinken, dat doe je niet" (...).' G.J. Heuver \& M.C. Bomhoff, Ziekenhuisbestuurders en de veiligheidscultuur, Zorgvisie 31 oktober 2016, www.zorgvisie.nl/ziekenhuisbestuurders-en-deveiligheidscultuur/. Coughlan e.a. zeggen hierover: 'Those with negative experiences of investigations, or punitive experiences, are less likely to report future incidents.' B. Coughlan, D. Powell \& M.F. Higgins, The second victim. A review, European Journal of Obstetrics \& Gynecology and Reproductive Biology 2017/213, p. 11-16, op p. 14. slot leidt individuele blame de aandacht af van noodzakelijke verbeteringen in het systeem. ${ }^{17}$ Dat maakt het moeilijk om in een blame-cultuur van incidenten te leren.

\section{The second victim (and the third, and the fourth ...)}

Blame-cultuur wordt eens te meer een probleem wanneer men zich realiseert dat de gevolgen van een incident weliswaar primair de patiënt en diens familie raken, maar dat de schade daartoe zeker niet beperkt blijft. Ook de zorgverleners (of zorgverlener) die bij de gebeurtenis betrokken zijn, kunnen daar dusdanig onder lijden dat zij in de literatuur worden aangeduid als 'second victim': ${ }^{18}$ een zorgverlener die door de gebeurtenis getraumatiseerd is en daar op psychisch, fysiek en professioneel vlak last van ondervindt. ${ }^{19}$ De gevolgen van een incident zijn voor de zorgverlener onder andere grote zorgen om de patiënt, ernstige schuldgevoelens, een gebrek aan zelfvertrouwen en angst voor reputatieschade. ${ }^{20}$ Zorgverleners zijn soms depressief, burned-out, vertonen op PTSS lijkende symptomen, of zijn gedurende langere tijd hyperalert. Zorgverleners kunnen zich hevig schamen. ${ }^{21}$ Onderzoek onder artsen in opleiding wees uit dat het meemaken van een incident kan leiden tot depersonalisatie, emotionele uitputting en een gebrek aan empathie. ${ }^{22}$ Sommige zorgverleners zijn suïcidaal. ${ }^{23}$

Het is niet moeilijk voor te stellen dat dit gevolgen heeft voor de kwaliteit van zorg die second victims leveren. The Institute of Healthcare Improvement introduceerde daarom naast de patiënt en de zorgverlener de organisatie als derde categorie mogelijke slachtoffers waarvoor beleid moet bestaan. ${ }^{24}$ Coughlan e.a. gebruiken de beeldspraak van een 'dominoeffect', waarin familie en vrienden van second victims het derde slachtoffer zijn en toekomstige patiënten als vierde catego-

16. Anoniem gepubliceerd, Waardeer de frisse blik van de co, Medisch Contact 23 september 2015.

17. J.J. Robertson \& B. Long, Suffering in silence. Medical error and its impact on healthcare providers, The Journal of Emergency Medicine (54) 2018, afl. 4, p. 402-409, op p. 404.

18. A.W. Wu, Medical error: the second victim. The doctor who makes the mistake needs help too, BMJ (320) 2000/7237, p. 726.

19. S.D. Scott, L.E. Hirschinger, K.R. Cox e.a., Caring for our own. Deploying a systemwide second victim rapid response team, The Joint Commission Journal on Quality and Patient Safety (36) 2010, afl. 5, p. 233-240, op p. 233.

20. D.L. Schwappach \& T.A. Boluarte, The emotional impact of medical error involvement on physicians. A call for leadership and organisational accountability, Swiss Medical Weekly 2009/139, p. 9-15.

21. K. Vanhaecht, E. Coeckelbergs, L. Schouten \& G. Zeeman, Onbedoelde schade treft ook arts. Impact van patiëntveiligheidsincident op zorgverleners wordt onderschat, Medisch Contact (37) 2018, p. 14-16, met schematisch overzicht van de aard en ernst van de symptomen op p. 16.

22. C.P. West, M.M. Huschka, P.J. Novotny e.a., Association of perceived medical errors with resident distress and empathy, JAMA 2006/296, afl. 9, p. 1071-1078.

23. T.D. Shanafelt, C.M. Balch, L. Dyrbye e.a., Special report: Suicidal ideation among American surgeons, The Archives of Surgery 2011/146, afl. 1, p. 54-62.

24. IHI White paper 'Respectful management of serious clinical adverse events', te downloaden via www.ihi.org/resources/Pages/IHIWhite Papers/RespectfulManagementSeriousClinicalAEsWhitePaper.aspx. 
rie van mogelijke slachtoffers worden gedefinieerd. ${ }^{25}, 26 \mathrm{Wie}$ er tweede, derde, vierde of vijfde slachtoffer is, doet er misschien niet zoveel toe. Duidelijk moge zijn dat de schadelijke gevolgen van een gebeurtenis verder reiken dan de gebeurtenis op zichzelf - en daarmee een direct risico vormen voor de kwaliteit en veiligheid van patiëntenzorg.

Er zijn werkwijzen die de gevolgen van een gebeurtenis voor zorgverleners verzachten en die er zelfs aan kunnen bijdragen dat de zorgverlener het gebeurde meerwaarde geeft door ervan te leren. Openheid over wat er is gebeurd, is daarin een centraal begrip. Voor zorgverleners is het belangrijk dat zij over de gebeurtenis kunnen praten met collega's. ${ }^{27}$ Daarom worden in Nederlandse ziekenhuizen sinds enkele jaren grote stappen gezet met het opzetten van 'peer support-netwerken'. ${ }^{28}$ Dat sluit aan bij het inzicht uit internationaal wetenschappelijk onderzoek dat opvang door collega's, met aandacht voor ervaring, leeftijd en functie dan wel specialisme, de voorkeur verdient boven opvang door BOT-teams (Bedrijfsopvangteam) of externe partijen. ${ }^{29}$ Overige copingmechanismen die bijdragen aan positieve verwerking (Plews-Ogan e.a. noemen dit 'post-traumatic growth') zijn (onder meer) praten over het incident met de patiënt en excuses aanbieden, vergeving, leren van het incident door een expert te worden over de oorzaak, maatregelen nemen ter voorkoming van eenzelfde soort incident in de toekomst en lesgeven over het incident. ${ }^{30}$ Robertson e.a. voegen daar op basis van een uitgebreide literatuurstudie focus op het systeem, focus op welzijn en cultuurverandering aan toe. ${ }^{31}$

\section{Van 'no blame' naar een 'just culture'}

Behalve dat het toekennen van blame schadelijk kan zijn, is het in veel opzichten ook achterhaald. Vaak kan het ontstaan van medische schade namelijk helemaal niet aan één persoon

25. Coughlan e.a. 2017, p. 11-16, op p. 12.

26. M. Higgins, The echoes of adverse events, The BMJ Opinion 2 maart 2017, https://blogs.bmj.com/bmj/2017/03/02/how-the-ghost-ofpatients-past-have-a-deeper-impact-than-we-may-think/.

27. Er is uitgebreid gepubliceerd over de noodzaak van opvang voor zorgverleners en hoe die opvang eruit zou moeten zien. Zie o.m. S.D. Seys e.a., Supporting involved healthcare professionals (second victims) following an adverse health event. A literature review, International Journal of Nursing Studies (50) 2013, p. 686 en Scott e.a. 2010. Aan de KU Leuven is Eva Van Gerven gepromoveerd op deze problematiek (E. Van Gerven, Health professionals as second victims of patient safety incidents. Impact on functioning and well-being (diss. Leuven), 2016) en bestaat een onderzoekslijn gewijd aan de second victim: www.secondvictim.be.

28. Enkele Nederlandse ziekenhuizen, zoals het OLVG Amsterdam en het UMC Groningen, doen al langere tijd ervaring op met peer support en functioneren op dit gebied als voortrekker. Parallel aan Leernetwerk OPEN is bovendien een Leernetwerk Peer Support gestart, dat ziekenhuizen helpt om peer support in het patiëntveiligheidsbeleid te implementeren, www.vvaa.nl/opleidingen/peer-support-in-de-zorg.

29. Coughlan e.a. 2018 , p. 14.

30. M. Plews-Ogan, N. May, J. Owens, M. Ardelt, J. Shapiro \& S.K. Bell, Wisdom in medicine: What helps physicians after a medical error?, Academic Medicine (91) 2016, afl. 2, p. 233-241.

31. J.J. Robertson \& B. Long, Suffering in silence: Medical error and its impact on health care providers, The Journal of Emergency Medicine (54) 2018, afl. 4, p. 402-209, op p. 405. worden toegeschreven. In het ontstaan van incidenten is in veel gevallen een grote rol weggelegd voor de systemische context, oftewel de zorginstelling, omdat deze de fout ${ }^{32}$ in de hand werkt of niet opvangt. Het beroemde Gatenkaasmodel van James Reason is behulpzaam om te illustreren wat hiermee wordt bedoeld. Dit Gatenkaasmodel laat zien dat fouten ontstaan door een samenspel van 'latente fouten' in het systeem (Reason vergelijkt deze met residente ziekteverwekkers) en 'acute fouten' van personen (Reason vergelijkt fouten in barrières en controles met het immuunsysteem van het lichaam). ${ }^{33}$ In het Gatenkaasmodel kan één individuele fout dus nooit tot schade leiden, omdat een goed systeem die fout zou opvangen.

Het systeemdenken gecombineerd met de behoefte aan een veilige meldcultuur was aanvankelijk aanleiding om te pleiten voor een 'no blame culture'. Veiligheid betekent echter niet 'onschendbaar', ${ }^{34}$ maar constructief en rechtvaardig. ${ }^{35}$ Daarom is de stap gezet van een no blame naar een just culture. De balans tussen veiligheid en verantwoordelijkheid wordt gezocht in een duidelijke grens tussen acceptabel en onacceptabel gedrag, en de verzekering dat zorgverleners altijd (ook juridisch) op onveilig gedrag worden aangesproken. In een just culture worden procedures waarin incidenten worden onderzocht echter zodanig ingericht dat zij geen toegevoegde schade veroorzaken door de zorgverlener als dader, of zelfs misdadiger, te behandelen. ${ }^{36}$

Sydney Dekker vraagt aandacht voor de uitgangspunten waarop een just culture-beleid gebaseerd is. ${ }^{37}$ Just culture in zijn huidige vorm draait nog steeds om de vraag wanneer er wel, en

32. In de gezondheidszorg is het woord 'fout' bijna taboe geworden, maar dat neemt niet weg dat fouten wel degelijk ontstaan door menselijke factoren. De crux zit hem in de manier waarop je daarmee omgaat. In een presentatie over de resultaten van de werkgroep Human Factors; Theorie en praktijk op het NFU Symposium 'Calamiteiten delen en leren van elkaar' op 15 november 2018 bracht L. Zwaan het als volgt onder woorden, dat de fout vaak wel gelegen is in de mens, maar de oplossing in het systeem.

33. J. Reason, Human error: Models and management, BMJ (Clinical Research Edition) (320) 2000/7237, p. 768-770.

34. In de regel wordt 'veilig' vaak opgevat als 'anoniem', of 'zonder mogelijke juridische consequenties'. Ik zou 'veilig' willen definiëren als het vertrouwen dat er respectvol met zorgverleners wordt omgegaan als zij een incident meemaken. Ik haal hier graag een citaat aan van een van de medewerkers die ik sprak in het kader van Leernetwerk OPEN: 'Dat heeft ook te maken met dat mensen het vertrouwen hebben dat veilig melden niet inhoudt dat je naam uit de melding wordt gehaald, maar dat veilig melden te maken heeft dat je Raad van Bestuur accepteert dat mensen fouten maken en dat niet gelijk je kop eraf wordt gehakt maar dat er wordt gezegd: hoe kunnen we dit voorkomen. Dat is het hele eieren eten.'

35. J. Legemaate, Just culture: juridische mogelijkheden en grenzen, NTvG (161) 2017/D1090, p. 1-3.

36. S. Dekker, The criminalization of human error in aviation and healthcare: A review, Safety Science (49) 2010, afl. 2, p. 121-127; C.M. Pettker $\&$ E.F. Funai, Getting it right when things go wrong, JAMA (303) 2010, afl. 10, p. 977-978.

37. S. Dekker, Just culture: Restoring trust and accountability in your organization, Boca Raton: CRC Press 2017. Zie ook S.W.A. Dekker \& H. Breaky, 'Just culture': Improving safety by achieving substantive, procedural and restorative justice, Safety Science (85) 2016, p. 187-193. 
wanneer er geen sanctie mag volgen na een incident. Dat daarbij de grens getrokken wordt tussen acceptabel (eerlijke vergissing) en onacceptabel gedrag (roekeloosheid) lijkt geruststellend, maar is dat, zeker in de gezondheidszorg, eigenlijk niet. Niemand komt 's ochtends naar zijn werk met de intentie om vandaag eens het verkeerde been af te zetten. Dekker legt de kwetsbaarheid van - wat hij noemt - retributieve just culture ${ }^{38}$ bloot door nader te bezien wat een eerlijke vergissing is, wat roekeloosheid is, wie daarover beslist en hoe objectief een dergelijk oordeel redelijkerwijs kan zijn:

'It is not that making such judgments is impossible. In fact, we do this often. It is, however important to remember that these are indeed judgments. They are not objective and not indisputable. To think that there comes a clear, uncontested point at which everybody says, "Yes, now the line has been crossed, this is negligence," is an illusion. What is "normal" versus "negligence" in a community, or a "reasonable level of skill", versus "recklessness" is infinitely negotiable. You can never really close the debate on this. As a result, there really is no line. There only are people who draw it. ${ }^{39}$

In de visie van Dekker kan een retributieve just culture daarom nooit een volledig veilige leeromgeving vormen. Dekker is van mening dat iemand wel op zijn of haar handelen kan worden aangesproken, maar dan op zodanige manier dat zorgverleners verantwoordelijkheid kunnen nemen voor dingen die zijn misgegaan buiten het bestraffende domein. Dekker zoekt daarvoor aansluiting bij het gedachtegoed van het herstelrecht, het idee dat het recht verbindend en herstellend moet zijn, en dat oplossingen daarom niet moeten worden opgelegd door een onafhankelijke rechtsprekende instantie of neutrale derde, maar moeten worden aangedragen door alle betrokkenen samen. ${ }^{40}$

\section{Ongewenste gevolgen van juridische procedures}

De aandacht voor herstelrecht staat niet op zichzelf, maar maakt onderdeel uit van innovatieve ontwikkelingen in het recht en de rechtstoepassing in het algemeen. Door te verbinden tussen just culture en het herstelrecht opent Dekker de deur van het patiëntveiligheidsdiscours naar tal van alternatieve, buitengerechtelijke of non-adversariële manieren om over het recht na te denken. Zoals men zich er in het patiëntveiligheidsdiscours in toenemende mate bewust van is dat blame schadelijk is en niet bijdraagt aan leren, zo bestaat er op verschillende plekken binnen de juridische discipline eveneens het besef dat een adversariële toepassing van het recht vaak

38. Eigenlijk kan beter worden gesproken van consequentialistische just culture, nu het in de gezondheidszorg niet gaat om straffen ter vergelding maar ter voorkoming van fouten in de toekomst. Zie voor het onderscheid o.m. Y. Buruma, Compassie en clementie in het strafrecht, in: B. van Stokkum (red.), Straf en herstel: ethische reflecties over sanctiedoeleinden, Den Haag: Boom Juridische uitgevers 2004, p. 151-168, op p. 156-162 (hierna: Buruma 2004a).

39. Dekker 2017, p. 3.

40. Dekker 2017, p. 115. maar nauwelijks aansluit bij de behoeften van betrokkenen en (daarom) schadelijk kan zijn. Het is dan ook goed om de blik te verruimen naar de bredere ontwikkelingen waar het herstelrechtgedachtegoed onderdeel van is (zie par. 7). Maar eerst sta ik kort stil bij recente inzichten over de gevolgen van juridische procedures. Waarom is het nodig om na te denken over de toepassing van het recht in de gezondheidszorg?

\subsection{De positie van de zorgverlener}

In de fase kort na een incident wordt hard gewerkt om 'blaming and shaming' te voorkomen. ${ }^{41} \mathrm{Als}$ dat al lukt, sluipt blame in een latere fase onmiskenbaar terug in het proces wanneer het gaat om de juridische afwikkeling van een gebeurtenis. Blame is namelijk een ingebakken onderdeel van ons juridische systeem. ${ }^{42}$ Een claim wordt op zijn merites beoordeeld naar de maatstaf van de toerekenbare tekortkoming van de behandelend zorgverlener. ${ }^{43}$ In het tuchtrecht staat de vraag centraal of de zorgverlener persoonlijk een verwijt kan worden gemaakt. ${ }^{44}$ Het tuchtrecht is misschien geen strafrecht, maar voor veel zorgverleners voelt dat wel zo. ${ }^{45}$ Dat geldt met name voor maatregelen die worden gepubliceerd - zoals reeds genoemd inmiddels weer teruggebracht tot beroepsbeperkende maatregelen. Juristen kunnen relativeren hoe persoonlijk een tuchtklacht of een claim moet worden opgevat, maar dat ligt voor zorgverleners toch wel anders. Een illustratie is het volgende citaat van een gynaecoloog over zijn ervaringen met het tuchtrecht: 'In de aanklacht werd ik genadeloos hard onderuitgehaald. De juridische taal was een compleet andere dan die ik kende. ${ }^{46}$

41. In ziekenhuizen worden bijv. kaartjes met 'do's and don'ts' uitgedeeld met tips hoe het beste op een melding kan worden gereageerd. Do: 'Hoe gaat het nu met jou?' Don't: 'Zo, dat is knap stom, je zult je wel waardeloos voelen!'

42. Zie hierover in de context van het Verenigd Koninkrijk Hodges, die hetzelfde verband legt tussen just culture en blame in het rechtssysteem. C. Hodges, Achieving a just culture that learns and improves, te verschijnen in: P. Vines \& A. Akkermans (red.), Unexpected consequences of compensation law.

43. Art. 6:74 jo. art. 7:453 BW. De mismatch tussen het aansprakelijkheidsrecht en de dagelijkse praktijk is recent ook in een andere context aangekaart door Zegveld, die promoveerde op de problemen die patiënten kunnen ervaren bij het vorderen van schadevergoeding bij medische fouten in transmurale zorg. C. Zegveld, Netwerkaansprakelijkheid voor gebrekkige samenhangende zorg (diss. Tilburg), Tilburg: Prisma Print 2018.

44. Art. 47 Wet BIG.

45. Zorgverleners geven in onderzoek naar de impact van het tuchtrecht aan zich 'gecriminaliseerd' te voelen, R. Friele, M. Hendriks, B.S. Laarman, R. Bouwman \& A. de Veer, Zorgverleners en burgers over het openbaar maken van door de tuchtrechter opgelegde berispingen en geldboetes, Nivel 2017, www.nivel.nl; L.M. Verhoef, J. Weenink, S. Winters, e.a., The disciplined healthcare professional: A qualitative interview study on the impact of the disciplinary process and imposed measures in the Netherlands, BMJ Open 2015;5:e009275, doi:10.1136/bmjopen-2015009275; F.Y. Alhafaji, B.J.M. Frederiks \& J. Legemaate, Ervaringen van klagers en aangeklaagde artsen met het tuchtrecht, TMD (13) 2009, afl. 3, p. 18-42.

46. F. Lim, De impact van een (bijna) incident of calamiteit op de zorgverlener, Nataal 2014, afl. 23, www.nataal.nl/artikelen/artikelen/ geboortezorg-zakelijk/de-impact-van-een-bijna-incident-of-calamiteitop-de-zorgverlener-3937/. 
De vraag rijst wat voor impact een conflictueuze claimafhandeling kan hebben op een zorgverlener met wie het na een incident toch al niet zo goed ging. Naar die vraag is in Nederland helaas nog geen empirisch onderzoek gedaan. Internationale literatuur is er wel, maar daarvan zijn de uitkomsten lastig te extrapoleren naar de Nederlandse context. Ten eerste wijden veel studies niet uit over de aard en inrichting van de 'compensation procedure' waar die betreffende studie op ziet, terwijl hier grote verschillen in kunnen worden vermoed. ${ }^{47}$ Veel studies zijn uitgevoerd in landen met een common lawstelsel. Daar heeft 'civil litigation' alleen al vanwege het gebruik van het kruisverhoor toch een aanzienlijk andere lading dan de wijze waarop in Nederland claims worden afgewikkeld, al rapporteren psychiater Charles e.a. dat de negatieve impact met name wordt veroorzaakt door de beschuldiging ('allegation') en niet door de fase van de procedure of de uitkomst:

'The results of this study indicate that, in terms of symptomatic and behavioral responses to malpractice litigation, it does not matter whether a physician goes to trial or even whether he or she is vindicated by a favorable trial outcome. In addition, as shown by comparing these results with our previous studies, those who have been sued, regardless of the phase of litigation or the outcome of the suit, generally report significantly more adverse symptoms and changes in behavior than non-sued physicians. ${ }^{2} 8$

We tasten dus niet helemaal in het duister. Internationaal onderzoek naar de afhandeling van claims leert ons in ieder geval dat het meemaken van een claimprocedure belastend is voor zorgverleners. ${ }^{49}$ Er bestaat zelfs een naam om de mogelijke gevolgen daarvan te beschrijven, 'Malpractice Stress syndrome', waarvan de symptomen worden vergeleken met PTSS. ${ }^{50}$

47. Zie over de problemen omtrent de generaliseerbaarheid van onderzoek naar de ervaringen met 'litigation' en 'compensation' L.J. Carroll, L.B. Connelly, N.M. Spearing, P. Cote, J. Buitenhuis \& J. Kenardy, Complexities in understanding the role of compensation-related factors on recovery from whiplash-associated disorders, discussion paper 2, Spine (Philia Pa 1976) (36) 2011, S316-321, en in het kader van een review over het effect van compensatieprocedures op de gezondheid van verkeersslachtoffers N. Elbers, Empowerment of injured claimants. Investigating claim factors, procedural justice and e-health, Vrije Universiteit Amsterdam 2012, op p. 15-27.

48. S.C. Charles, C. Pyskoty \& A. Nelson, Physicians on trial - self-reported reactions to malpractice trials, Western Journal of Medicine (148) 1988, afl. 3, p. 358-360, op p. 359.

49. C.M. Balch, M.R. Oreskovich, L.N. Dyrbye e.a., Personal consequences of malpractice lawsuits on American surgeons, Journal American College of Surgeons 2011/213, afl. 5, p. 657-667; S.C. Charles, Physicians' self-reports of reactions to malpractice litigation, American Journal of Psychiatry 1984/141, p. 563-565.

50. N.A. Ryll, Living through litigation: Malpractice stress syndrome, Journal of Radiology Nursing (34) 2015, afl. 1, p. 35-38; A. Fileni, N. Magnavita \& F. Mammi e.a., Il fenomeno dello stress da malpractice nei radiologi e radioterapisti. Percezione del problema e conseguenze (Malpractice stress syndrome in radiologists and radiotherapists. Perceived causes and consequences), Radiology Medicine 2007/112, p. 1069-1084.
Uit onderzoek naar de ervaringen met (tucht)klachtprocedures weten we eveneens dat dit voor zorgverleners vaak belastende ervaringen zijn. Recent onderzoek door de KU Leuven toont aan dat zorgverleners die na een incident ook een tuchtzaak meemaken meer gezondheidsklachten rapporteren dan hun collega's die wel meemaakten dat er iets misging, maar geen tuchtklacht kregen, en dat de klachten bij hen ook langer duren. ${ }^{51}$ Nederlandse respondenten in een onderzoek onder zorgverleners die een tuchtprocedure meemaakten, rapporteerden eveneens een negatieve impact op hun gezondheid..$^{52}$ Hetzelfde geldt voor een grootschalig onderzoek naar de impact van (alle vormen van) klachtenprocedures op zorgverleners in het Verenigd Koninkrijk. ${ }^{53}$ In de literatuur wordt voorts een verband gelegd tussen het meemaken van een juridische procedure en defensief gedrag. ${ }^{54}$ Daarmee wordt bedoeld dat het motief voor behandeling niet primair is dat die behandeling nodig is, maar dat wordt behandeld om een klacht of claim te voorkomen. ${ }^{55}$ Voor sommige zorgverleners is de (tucht)zaak zelfs een reden om helemaal te stoppen met het werk als zorgverlener. ${ }^{56}$

Specifieke factoren die (tucht)klachtprocedures belastend maken, zijn de lange duur van een procedure, de onzekerheid over het verloop en de uitkomst, en de gejuridiseerde en formele gang van zaken. ${ }^{57} \mathrm{Bij}$ dat laatste kan het gaan om simpele dingen, zoals de opstelling van een zaal of de afstandelijke hou-

51. Nieuwsbericht 22 februari 2019: 'Betere begeleiding zorgverleners vereist na patiëntveiligheidsincident, klacht of tuchtzaak. Impact op zorgverlener nog steeds onderschat.' Zie over het onderzoek www.kuleuven.be/samenwerking/ligb/nieuws/nieuwsbericht22022019.

52. Friele e.a. 2017.

53. T. Bourne, L. Wynants, M. Peters e.a., The impact of complaints procedures on the welfare, health and clinical practise of 7926 doctors in the UK. A cross-sectional survey, BMJ Open 2015;5:e006687, doi:10.1136/ bmjopen-2014-006687; T. Bourne, J. Vanderhaegen, R. Vranken e.a., Doctors' experiences and their perception of the most stressful aspects of complaints processes in the UK. An analysis of qualitative survey data, BMJ Open 2016, afl. 6, p. 1-10, doi:10.1136/bmjopen2016-011711.

54. In de literatuur meestal aangeduid als 'defensive medicine'. D.M. Studdert, M.M. Mello, W.M. Sage e.a., Defensive medicine among high-risk specialist physicians in a volatile malpractice environment, JAMA 2005/293, afl. 21, p. 2609-2617.

55. De definiëring van 'defensive medicine' is nog wel ingewikkeld; maakt de vraag of het handelen klinisch niet noodzakelijk is het handelen defensief, of gaat het om de intrinsieke motivatie voor het handelen? Zo is in Denemarken in 2017 een kwalitatief onderzoek uitgevoerd om te onderzoeken hoe zorgverleners zelf 'defensive medicine' begrijpen: E. Assing Hvidt, J. Lykkegaard, L. Bjornskov Pedersen e.a., How is defensive medicine understood and experienced in a primary care setting? A qualitative focus group study among Danish general practitioners, BMJ Open 2017;7(12). Defensief gedrag kan zich voorts uiten door overbehandeling, zoals het doen van onnodige tests of doorverwijzen naar specialistische zorg wanneer dat niet nodig is. Defensief gedrag kan zich ook uiten in het mijden van kwetsbare patiënten en risicovolle behandelingen, of het mijden van patiënten en behandelingen waarmee men een negatieve ervaring heeft gehad. Robertson \& Long 2018, p. 405.

56. Voor wat betreft het tuchtrecht: Friele e.a. 2016, Verhoef e.a. 2015 Alhafaji e.a. 2009. Voor wat betreft het formele klachtrecht onder de WKCZ: J.J.M. Bruers, B.A.F.M. van Dam, R. Gorter \& M.A.J. Eijkman, Het welbevinden van tandartsen na een klachtenprocedure, Nederlands Tijdschrift voor Tandheelkunde 2015/122, p. 41-48.

57. Friele e.a. 2017, p. 16-17. In internationale zin: Bourne e.a. 2016. 
ding van het rechtsprekend college, bijvoorbeeld wanneer die partijen geen hand geven of zich niet voorstellen. ${ }^{58}$ Waarschijnlijk kan worden aangenomen dat dit ook geldt voor een claimprocedure.

\subsection{Depositie van patiënten}

Als er aanleiding was om te denken dat patiënten op hun beurt iets opschieten met het aansprakelijkheidsrecht, zou het goed verdedigbaar zijn dat zorgverleners nu eenmaal het een en ander te dulden hebben wanneer zij een patiënt schade hebben berokkend. Die aanwijzingen zijn er echter niet in overvloed, sterker nog, voor veel patiënten is een claimprocedure belastend en soms zelfs schadelijk. Gutheil e.a. introduceerden het woord 'critogene schade', letterlijk te vertalen als 'schade veroorzaakt door het recht'. ${ }^{59}$ Critogene schade treedt niet alleen op wanneer het recht 'slecht werkt', maar ook wanneer een procedure precies verloopt zoals zou moeten. Een andere bekende term om hetzelfde fenomeen te omschrijven is 'secundaire victimisatie'.

Secundaire victimisatie kan optreden door de mismatch tussen behoeften van patiënten en het doel van een claimprocedure. Patiënten die meemaken dat er iets misgaat tijdens hun behandeling hebben namelijk veel behoeften die op het eerste gezicht weinig te maken hebben met het aansprakelijkheidsrecht, maar die wel regelmatig de claimbehandeling binnensijpelen. ${ }^{60}$ Patiënten willen ten eerste goed worden gënformeerd. $\mathrm{Zij}$ willen weten wat er is gebeurd, waarom het is gebeurd, wat er wordt gedaan om de schade te beperken, en wat de zorgaanbieder voor maatregelen neemt om te voorkomen dat hetzelfde nog een keer gebeurt. Het is voor patiënten heel belangrijk dat er van een incident wordt geleerd. $\mathrm{Zij}$ hechten er waarde aan dat een zorgverlener verantwoordelijkheid neemt, laat blijken dat hij of zij meeleeft en,

58. Alhafaji e.a. 2009 , p. 29.

59. T.G. Gutheil, H. Bursztajn, A. Brodsky \& L.H. Strasburger. (2000). Preventing "Critogenic" Harms: Minimizing Emotional Injury from Civil Litigation. The Journal of Psychiatry \& Law (28) 2000, afl. 1, p. 5-18. Akkermans \& Van Wees 2007, p. 109. Andere benamingen zijn 'litigation stress syndrome' en 'forensic stress syndrome'.

60. In Nederland is kwalitatief onderzoek verricht naar de behoeften van patiënten na een incident door Smeehuizen e.a., zie J.L. Smeehuijzen, K.A.P.C. van Wees, A.J. Akkermans, J. Legemaate, S. van Buschbach \& L. Hulst, Opvang en schadeafwikkeling bij onbedoelde gevolgen van medische schade, Vrije Universiteit Amsterdam 2013, meer specifiek op p. 10-13 en 70-101. Iedema e.a. interviewden 100 patiënten over hun ervaringen met open disclosure in Australië: R. Iedema, S. Allen, K. Britton e.a., The ' 100 patient stories' project. Patient and family member views on how clinicians (should) enact. Open disclosure - A qualitative study, British Medical Journal (Clinical Research Edition) 2011, 343(n/a), d4423. Gallagher e.a. organiseerden dertien focusgroepen om te achterhalen hoe patiënten en artsen aankijken tegen disclosure, zie T.H. Gallagher, A.D. Waterman, A.G. Ebers, V.J. Fraser \& W. Levinson, Patients' and physicians' attitudes regarding the disclosure of medical errors, JAMA 2003/289, afl. 8, p. 1001-1007, doi:10.1001/jama. 289.8.1001. indien gepast, zijn of haar excuses aanbiedt. ${ }^{61}$ Patiënten die financiële schade lijden door een medische fout, willen dat deze schade fatsoenlijk wordt gecompenseerd, maar dat is vaak niet hun enige of zelfs belangrijkste drijfveer. Uit onderzoek waarin patiënten wordt gevraagd waarom zij een claim indienden, blijkt dat veel van hen dit niet alleen deden omdat zij schadevergoeding wilden, maar ook omdat zij zich zorgen maakten over de kwaliteit van zorg, omdat zij een betere verklaring wilden voor wat hun was overkomen, en omdat zij vonden dat de zorginstelling de verantwoordelijkheid moest nemen voor wat er was gebeurd. ${ }^{62}$

Patiënten dienen ook klachten of claims in omdat zij niet weten hoe zij een zorg of een vraag op een andere manier aan de orde kunnen stellen. ${ }^{63}$ Procedures in de gezondheidszorg zijn vaak verkokerd op basis van juridisch relevante onderscheidingen die voor patiënten moeilijk te begrijpen zijn. Daarmee wordt bedoeld dat juridische procedures zijn toegespitst op één aspect van de afwikkeling van een incident, met als gevolg dat één belang of behoefte centraal staat. In calamiteitenonderzoek wordt een mogelijke calamiteit onderzocht, in een klachtenprocedure probeert men een oplossing te vinden voor onvrede, en in een claimprocedure staat het recht op financiële tegemoetkoming centraal. Voor patiënten is het onderscheid tussen procedures en het daarbij behorende verschil in openheid, aandacht en begeleiding verwarrend en onbevredigend. ${ }^{64}$ Voor hen ontbreekt het overzicht en raakt communicatie versnipperd, omdat zij iedere keer met een andere functionaris van doen hebben. Bovendien kunnen juridische labels in de weg staan aan de toegankelijkheid van procedures, omdat het beladen termen zijn. Het is bekend dat sommige patiënten geen klacht indienen omdat zij niet als 'klager' bekend willen staan. ${ }^{65}$ Het woord 'claim' is eerder ter discussie gesteld omdat het een assertiviteit veronderstelt die

61. Smeehuijzen e.a. 2013. Dat dit nog altijd niet op de juiste manier gebeurt, blijkt uit de voorlopige resultaten van het onderzoek 'Slachtoffers aan het woord', dat VUmc en Nivel in opdracht van SASS uitvoeren naar de ervaringen van patiënten met de afhandeling van calamiteiten. Zie over het onderzoek: www.sass.nl/projecten/slachtoffers-aanwoord/.

62. C. Vincent, M. Young \& A. Phillips, Why do people sue doctors? A study of patients and relatives taking legal action, The Lancet 1994, p. $1609-1613$, op p. 1612.

63. Zie B.S. Laarman e.a., OPEN: open en eerlijke omgang na klachten en incidenten in het ziekenhuis, Utrecht: Nivel 2016, p. 52. Ook in de evaluatie van de GOMA wordt aan deze problematiek aandacht besteed. Zie B.S. Laarman, T. Coppenhagen, R. Bouwman \& R.D. Friele, Ervaringen met de GOMA. Ervaringen met deel A van de Gedragscode Openheid na medische incidenten; betere afwikkeling Medische Aansprakelijkheid (2010). Welke vragen spelen bij de implementatie van een open beleid in ziekenhuizen?, Utrecht: Nivel 2018, met name in hoofdstuk 5.

64. Laarman e.a. 2018, p. 6, 13, 26-27 en 29; 2016, p. 49; J.G. Sijmons e.a., Tweede evaluatie Wet op de beroepen in de individuele gezondheidszorg, Den Haag: ZonMw 2013, p. 14.

65. M. Bomhoff, N. Paus \& R. Friele, Niets te klagen: onderzoek naar uitingen van ongenoegen in verzorgings- en verpleeghuizen, Utrecht: Nivel 2013. 
de patiënt op het klagersbankje plaatst, waar hij mogelijk liever wegbleef. $^{66}$

In theorie is een claimprocedure overigens helemaal niet per definitie ongeschikt om aan de immateriële behoeften van patiënten tegemoet te komen. ${ }^{67}$ Gutheil e.a. noemen de mogelijkheid om de wederpartij ter verantwoording te roepen, de bevestiging van het gelijk en de aanwending van het aansprakelijkheidsrecht voor rouwverwerking als mogelijke 'critogenic benefits'. Het probleem is echter dat de manier waarop veel claims worden afgehandeld zoveel negatieve bijwerkingen kan hebben. Dat juridische procedures voor zorgverleners zwaar kunnen zijn, hebben we gezien, maar ook een patiënt die een claim indient, komt vaak in een formele procedure terecht waar in de regel maar weinig ruimte is voor de dialoog waar veel patiënten naar op zoek zijn. Sterker nog, het juridische conflict staat daar waarschijnlijk eerder aan in de weg dan dat dit dialoog in de hand werkt. Dat is bijvoorbeeld het geval wanneer patiënten de behandelrelatie met hun zorgverlener willen voortzetten of zelfs willen herstellen, maar daar door het juridische conflict niet in slagen omdat de zorgverlener door zijn of haar belangenbehartiger wordt geadviseerd de patiënt naar een collega door te verwijzen, of het contact hangende de procedure te verbreken. Hetzelfde geldt voor belangenbehartigers aan patiëntzijde die direct contact tussen zorgaanbieder en patiënt verhinderen of afraden. Claimprocedures hebben bovendien maar een beperkte kans op een succesvolle afloop $^{68}$ - al kan de impact van een procedure los van de uitkomst staan. ${ }^{69}$

Tot slot is de procedure zelf vaak belastend. Belastende factoren zijn de lange duur van de procedure, evenals het ervaren gebrek aan regie en het herhaald ondergaan van medisch onderzoek. Daarnaast wordt het adversariële karakter van schadeafwikkeling als belastend ervaren. ${ }^{70}$ Dat uit zich voor patiënten dan met name in de opstelling van de aangesproken partij dan wel zijn of haar verzekeraar, bijvoorbeeld wanneer de gestelde gang van zaken wordt betwist en aansprakelijkheid wordt ontkend. ${ }^{71}$ Patiënten die een tuchtklacht hebben inge-

66. Beeldspraak afkomstig van Geertruid van Wassenaer. Akkermans en ik bespraken deze kwestie eerder in B.S. Laarman \& A.J. Akkermans, De afwikkeling van medische schade onder de Wkkgz, TVP 2017, afl. 3, p. 59.

67. Akkermans \& Van Wees 2007.

68. Centramed erkende of schikte tussen 1994 en $201637 \%$ van de claims. Bron: www.centramed.nl/over-centramed/centramed-in-cijfers. MediRisk erkende of schikte in $201644 \%$ van de claims. Bron: www.medirisk.nl/kennisbank-preventie/feiten-en-cijfers.

69. T.R. Tyler, What is procedural justice? Criteria used by citizens to assess the fairness of legal procedures, Law \& Society Review 1988, p. 103-136. E.A. Lind e.a., In the eye of the beholder. Tort litigants' evaluations of their experiences in the civil justice system, Law \& Society Review (24) 1990, p. 953-957. Toegankelijke Nederlandstalige literatuur over procedurele rechtvaardigheid is bijv. K. van den Bos, Rechtvaardigheid en onzekerheid, in: W.L. Tiemeijer, C.A. Thomas \& H.M. Prast (red.), De menselijke beslisser, Amsterdam: Amsterdam University Press 2009, p. 89-105.

70. Smeehuijzen e.a. 2013, p. 95; Akkermans \& Van Wees 2007, p. 106-107.

71. Smeehuijzen e.a. 2013, p. 101. diend, kunnen net als artsen de formele afhandeling van een klacht als belastend ervaren. ${ }^{72}$

\section{The Comprehensive Law Movement}

Blame-cultuur, al helemaal als die zich openbaart in de vorm van adversariële juridische procedures, staat in de weg aan een open en eerlijke reactie na een gebeurtenis en kan een negatieve impact hebben op het herstel van patiënt en het welbevinden van zorgverlener(s) en op de kwaliteit van zorg. Daarom streeft de gezondheidszorg naar een just culture. Ook door juristen wordt gezocht naar alternatieve manieren van rechtstoepassing die beter aansluiten bij de behoeften van iedereen die bij de gebeurtenis betrokken is. In bijna alle ontwikkelde rechtsstelsels in de wereld zijn op theoretisch en praktisch niveau ontwikkelingen zichtbaar waarbij wordt gezocht naar manieren om het recht en juridische procedures beter af te stemmen op de behoeften van deelnemers en samenleving. Voordat we ons verder toeleggen op herstelrecht, verbreden we de blik daarom kort naar wat de Amerikaanse auteur Susan Daicoff 'The Comprehensive Law Movement' heeft genoemd. ${ }^{73}$

Daicoff brengt onder de vlag van 'The Comprehensive Law Movement' verschillende belangrijke denkrichtingen samen. ${ }^{74}$ 'Comprehensive Law' is niet gekoppeld aan één werkwijze of zelfs één theoretische benadering. Daicoff onderscheidt negen pijlers (zij spreekt van 'vectors'), die zich vaak onafhankelijk van elkaar hebben ontwikkeld in verschillende rechtsgebieden, onder andere in het familierecht en het strafrecht. Als belangrijkste gezamenlijke doel zou kunnen worden aangewezen het optimaliseren van het welzijn van betrokkenen in juridische procedures. Verschillen bestaan naargelang op welk aspect van welzijn de nadruk wordt gelegd (welzijn in emotionele zin of relationele zin, de morele ontwikkeling of herintegratie van daders, enzovoort) en welk mechanisme op de voorgrond staat (andere procedures, andere aanpak door belangenbehartigers, andere rolopvatting door de rechter of een ander schadebegrip).

In alle pijlers wordt aangemoedigd om buiten het traditionele juridische kader te denken en te doen. Comprehensive Law is creatief en interdisciplinair. Vijf van de negen pijlers die Daicoff onderscheidt (therapeutic jurisprudence, creative problem solving, procedural justice of procedurele rechtvaardigheid, preventive law en holistic justice) categoriseert zij als theoretische

72. Alhafaji e.a. 2009 , p. 39.

73. S. Daicoff, The Comprehensive Law Movement: An emerging approach to legal problems, Scandinavian Studies in Law (49) 2006, p. 109-128.

74. De verschillende benaderingen van rechtsbeoefening zijn niet allemaa vertaald, omdat niet voor alle stromingen een adequate vertaling bestaat. Dat is bijv. het geval voor therapeutic jurisprudence, reden voor Van Wees en Akkermans om de term niet te vertalen, omdat dit al snel tot misvertaling leidt. De term jurisprudence dient bijv. niet te worden verward met het Nederlandse woord jurisprudentie. Jurisprudence staat kort gezegd voor de wetenschappelijke bestudering van het recht(ssysteem). K.A.P.C. van Wees \& A.J. Akkermans, Therapeutic jurisprudence: de studie van de gezondheidseffecten van het recht, TVP 2007, afl. 4, p. 139-141. 
benaderingen van het recht. Therapeutic jurisprudence stelt zichzelf de vraag hoe procedures (anti)therapeutisch kunnen werken in herstel ${ }^{75}$ creative problem solving zoekt de meest creatieve oplossing voor een probleem, ${ }^{76}$ preventive law draait om het voorkomen van procedures, ${ }^{77}$ en holistic law benadert een juridisch probleem binnen de bredere context van de psychologische en fysieke gezondheid van een cliënt. ${ }^{78}$ Holistic law kan een persoonlijke en spirituele tint krijgen naarmate de holistische advocaat een bredere opvatting heeft van welke context relevant is voor het juridische probleem. ${ }^{79}$ Procedurele rechtvaardigheid draait om de vraag of mensen zich rechtvaardig behandeld voelen. ${ }^{80}$

De grenzen tussen deze benaderingen zijn allesbehalve afgebakend en volgens Daicoff zou ieder van deze pijlers als theoretische onderbouwing van The Comprehensive Law Movement kunnen dienen. ${ }^{81}$ De overige vier pijlers die Daicoff onderscheidt (herstelrecht, ${ }^{82}$ collaborative law, ${ }^{83}$ transformatieve

75. Daicoff 2006, p. 120; M. King, A. Freiberg, B. Batagol \& R. Hyams, Non-adversarial justice, Sydney: The New Federation Press 2009, p. 22-39. Verder D. Wexler, Therapeutic jurisprudence: An overview, Thomas M. Cooley Law Review (17) 2000 p. 125; D.B. Wexler, Two decades of therapeutic jurisprudence, Touro Law Review (24) 2008, p. 17.

76. Daicoff 2006, p. 124; King e.a. 2009, p. 65-74; T.D. Barton \& C. Menkel-Meadow, Toward another view of legal negotiation. The structure of problem solving, UCLA Law Review (31) 1984, p. 754, en meer specifiek over de rolopvatting van een advocaat: C.J. Menkel-Meadow, When winning isn't everything. The lawyer as problem solver, (28) Hofstra Law Review 2000, p. 905 en T.D. Barton, Creative problem solving: Purpose, meaning, and values, California Western Law Review (34) 1998, p. 273.

77. Daicoff 2006, p. 121; King e.a. 2009, p. 80-88; T.D. Barton, Preventive law and problem solving. Lawyering for the future, 2009, www.preventivelawyer.org; en uit de integratie van therapeutic jurisprudence en preventive law, als voorgestaan door Stolle e.a., waarbij preventive law de praktische handvatten biedt om het recht meer therapeutisch toe te passen. Een kort en toegankelijk stuk hoe dat vorm krijgt, is D.P. Stolle \& D.B. Wexler, Preventive law and therapeutic jurisprudence: A symbiotic relationship, Preventive Law Reporter (16) 1997, afl. 4, p. 15-52; meer uitgebreid: D.P. Stolle, D.B. Wexler, B.J. Winick \& E.A. Dauer, Integrating preventive law and therapeutic jurisprudence. A law and psychology based approach to lawyering, California Western Law Review (34) 1997, afl. 1, p. 1215-1239.

78. Daicoff 2006, p. 119; J.K. Wright, Lawyers as peacemakers. Practicing holistic, problem-solving law, American Bar Association 2010; C.G. Lee, B.J. Ostrom \& M. Kleiman, The measure of good lawyering. Evaluating holistic defense in practice, Albany Law Review (78) 2014, p. 1215; W. van Zyverden, Holistic lawyering: A comprehensive approach to dispute resolution, Boston University Public Interest Law Journal (3) 1993, afl. 5, p. 5-8; A.P. Harris, Toward lawyering as peacemaking. A seminar on mindfulness, morality, and professional identity, Journal of Legal Education (61) 2012, p. 647.

79. King e.a. 2009, p. 87: 'In its broadest sense, a holistic law approach sees the legal problem as part of a quest for greater wholeness and meaning (...) a need for spiritual and emotional healing, and as a means for the lawyer and client to work together (...).' Van Zyverden 1993; Harris 2012.

80. Daicoff 2006, p. 123. Zie ook de literatuur in noot 70. L. Klamer \& B. Bethlehem, Procedurele rechtvaardigheid: kunnen inzichten uit onderzoek naar procedurele rechtvaardigheid bijdragen aan de verwezenlijking van de functies van het aansprakelijkheidsrecht?, TVP 2007, afl. 4, p. 119-124; Akkermans \& Van Wees 2007.

81. Daicoff 2006, p. 127.

82. Daicoff 2006, p. 116; King e.a. 2009, p. 39-65; zie verder par. 8. mediation ${ }^{84}$ en problem solving courts of problem solving justice, in Nederland ook wel probleemoplossend strafrecht of responsieve rechtspraak ${ }^{85}$ ) koppelen een theoretische benadering van recht aan concrete wijzen van conflictoplossing. ${ }^{86} \mathrm{De}$ pijlers hebben met elkaar gemeen dat zij verder kijken dan het juridische gelijk en zoeken naar de belangen achter het juridische conflict, zodat er kan worden gewerkt aan het herstel van relaties en emotioneel welzijn van de betrokken personen. ${ }^{87}$ Ook de theoretische en praktische pijlers zijn met elkaar verweven. Zo kan herstelrecht, creative problem solving of preventive law een manier zijn om het recht meer therapeutisch toe te passen. ${ }^{88}$

Comprehensive Law is niet uitsluitend non-adversarieel, maar ziet het toernooimodel wel als de minst optimale methode voor het oplossen van een conflict. Vermoedelijk is dat ook het grootste onderscheid met het nauw verwante Australische label van 'non-adversarial justice'. Michael King e.a. gebruiken de term 'non-adversarial justice' als overkoepelend begrip voor verschillende benaderingen van het recht die zijn gericht op verbindende wijzen van conflictoplossing in de civiele en de publieke sector. ${ }^{89}$ Non-adversarial justice is gericht op preventie in plaats van oplossingen achteraf, samenwerking in plaats van conflict en oplossing van het onderliggende probleem in plaats van zuivere geschilbeslechting. In die zin is 'non-adversarial justice' ook 'comprehensive'. Hoewel King e.a. bena-

83. Daicoff 2006, p. 118; King e.a. 2009, p. 124 (onder 'Non-adversarial processes in family law'); M.J. Vonk, Een blik in de keuken van The Victoria Collaborative Family Law Group in Victoria, BC, Canada: de overlegscheiding, REP 2011, afl. 2, p. 66-69.

84. R.A. Baruch Bush \& J.P. Folger, The promise of mediation. The transformative approach to conflict, San Francisco: Jossey-Bass 2005; Daicoff 2006, p. 117; A. Brenninkmeijer, D. Bonenkamp, K. van Oyen \& H. Prein (red.), Handboek mediation, Den Haag: Sdu Uitgevers 2017, p. 288-309.

85. Daicoff 2006, p. 126; King e.a. 2009, p. 138-170; ook wordt wel gesproken van 'problem solving justice'. In Nederland heeft Schmidt een mooi proefschrift geschreven over problem solving courts: H.G. Schmidt, Probleemoplossend strafrecht: en het ideaal van responsieve rechtspraak (diss. Rotterdam), 2011. De constatering dat veel literatuur omtrent problem solving justice afkomstig is uit de VS of Australië bracht de redactie van de Utrecht Law Review ertoe Europese ontwikkelingen in kaart te brengen. De resultaten zijn in januari 2019 gepubliceerd in een speciale uitgave rond het thema 'Problem solving justice', voornamelijk in bestuurs- en strafrecht. Het redactioneel geeft een overzicht van de bijdragen uit Engeland en Wales, Finland, Frankrijk, Italië, Nederland en Polen. Zie M. Boone \& P. Langbroek, Problem solving justice: European approaches, en specifiek voor de Nederlandse ontwikkelingen van dezelfde auteurs: Problem-solving initiatives in administrative and criminal law in the Netherlands, Utrecht Law Review (14) 2018, afl. 3, via www.utrechtlawreview.org/44/volume/14/issue/3/.

86. Sommige van de pijlers vallen ook onder wat men in het civiele recht Alternative Dispute Resolution (ADR) pleegt te noemen. Onder die noemer vallen werkwijzen die buitengerechtelijk zijn en soms restorative, zoals mediation, maar daar niet altijd specifiek op gericht zijn en soms niet eens uitgesproken 'non-adversarial' zijn. Denk aan arbitrage, die qua formele procedures dichter bij klassiek procederen ligt dan mediation. King e.a. 2009, p. 101.

87. In Nederland spreekt men dan ook wel van het 'harmoniemodel', als tegenovergesteld aan het 'toernooimodel'.

88. J. Braithwaite, Restorative justice and therapeutic jurisprudence, Criminal Law Bulletin 2002, p. 244-262 en de literatuur in noot 78.

89. King e.a. 2009. 
drukken dat zij non-adversarial justice niet zien als vervanging maar als aanvulling op meer traditionele en adversarial benaderingen van het recht, ${ }^{90}$ karakteriseert het begrip 'non-adversarial' zich toch voornamelijk door wat het niet is: het is niet op basis van tegenspraak. Comprehensive Law is in die zin een completer (what's in a name?) begrip dan non-adversarial justice, al moeten de verschillen niet worden overdreven. ${ }^{91}$

\section{Herstelrecht}

\subsection{Herstelrecht en just culture}

Zoals het recht door een therapeutische bril kan worden bekeken, zo geldt dat natuurlijk ook voor procedures in de gezondheidszorg. Dekker legt aan zijn just culture-benadering een herstelgericht perspectief ten grondslag, waarmee je niet alleen iets kunt zeggen over de manier waarop een cultuur functioneert in termen van herstel, maar waarmee eveneens praktische handvatten zijn gegeven hoe het anders kan. Wat is herstelrecht nu precies? Dat wordt op verschillende manieren onder woorden gebracht, maar de meest geaccepteerde omschrijving van herstelrecht is afkomstig van Tony Marshall en luidt als volgt:

'Restorative justice is a process whereby all the parties with a stake in a particular offense come together to resolve collectively how to deal with the aftermath of the offense and its implications for the future. ${ }^{, 92}$

In deze definitie lijkt herstelrecht op mediation (een bijeenkomst met het doel om partijen dichter bij elkaar te brengen), maar het is toch niet helemaal hetzelfde. ${ }^{93}$ Zehr benoemt als belangrijke verschillen de ongelijkwaardige positie tussen partijen en hun ongelijke aandeel in het ontstaan van de gebeurtenis, de mogelijkheid om herstelrecht toe te passen zonder dat er sprake is van een 'conflict', en de mogelijkheid van herstelrecht zonder een fysieke bijeenkomst van de betrokkenen. Als verschil met mediation kan eveneens worden genoemd de betrokkenheid van de gemeenschap in een restorative aanpak. Dat neemt niet weg dat mediation, afhankelijk van de soort mediation, de stijl van de mediator en het type situatie waar mediation voor wordt ingezet, wel herstelge-

90. 'Rather than being mutually exclusive opposites, we prefer to conceive of adversarialism and non-adversarialism as a continuum, a sliding scale upon which various legal processes sit.' King e.a. 2009, p. 5. Evenals Daicoff (2006) overigens, op p. 128.

91. Je zou ook kunnen zeggen dat sommige van de werkwijzen die onder het begrip 'comprehensive' vallen onder het begrip 'non-adversarial justice' kunnen worden geschaard. Ik laat het hier maar bij.

92. T.F. Marshall, Restorative Justice: An overview, St. Paul: Centre for Restorative Justice and Mediation 1998.

93. H. Zehr, Little book of restorative justice: Revised and updated, New York: Good Books 2015, p. 15-16. richt kan zijn ${ }^{94}$ en ook als herstelgerichte voorziening wordt toegepast (waarover meer in par. 9).

Andere bekende toepassingen van herstelrecht zijn herstelconferenties ('conferencing') en 'circles', waarvoor mij geen Nederlandse vertaling bekend is. De herstelconferentie is een methode die wordt toegepast in het familierecht en het strafrecht waarbij de gemeenschap van belanghebbenden betrokken wordt bij het bereiken en uitvoeren van een overeenkomst. Dat kan een overeenkomst zijn over de zorg voor kwetsbare personen, een omgangsregeling, of over de re-integratie van jeugddelinquenten en de nasleep van hun daden ten opzichte van het slachtoffer. Een herstelconferentie wordt begeleid door een neutrale derde. Dat kan een mediator zijn. ${ }^{95}$ Circles lijken op herstelconferenties, waarbij de deelnemers in een kring zitten om wederzijds respect te bevorderen, en een 'talking piece' wordt doorgegeven om te verzekeren dat iedereen kan uitpraten. ${ }^{96}$

Wat in een concrete situatie een restorative aanpak is, kan worden bepaald door het stellen van gidsende vragen ('guiding questions') waarvan de beantwoording in een concrete situatie de meest passende aanpak bepaalt. ${ }^{97}$

\section{Gidsende vragen van herstelrecht}

1. Wie zijn er benadeeld?

2. Wat zijn hun behoeften?

3. Wiens verantwoordelijkheid is het om daaraan tegemoet te komen?

4. Waarom is dit gebeurd?

5. Wie heeft er een belang in deze situatie?

6. Wat is het juiste proces om belanghebbenden te betrekken bij een poging om het goed te maken en te voorkomen dat het nog een keer gebeurt?

Waarom Dekker nu kiest voor herstelrecht - in plaats van één van de andere pijlers van The Comprehensive Law Movement, die hij niet bespreekt - legt hij niet verder uit dan dat ' $r$ ] ecognizing the ways in which they [belanghebbenden; BL] hurt and responding to their needs is necessary if you want

94. Dick Allewijn, hoogleraar Mediation aan de Vrije Universiteit, merkte bij de conceptversie van dit artikel hierover het volgende op: 'Ja, dus in mijn (mediation)wereld is het zo: er is iets aan de hand, de mediator makt een conflictdiagnose (geen conflict? Des te beter), en levert dan maatwerk, en zo zal mediation in een kwestie waar sprake blijkt te zijn van een overtreding of een fout het karakter krijgen van een herstelproces. Dat is dus bijna hetzelfde als jouw volgende alinea, alleen met één voorvraag: is er iemand eenzijdig benadeeld?' Zo blijkt maar weer dat er een veelheid aan werkwijzen weliswaar niet per definitie restorative is, maar wel kan zijn, en dat belangrijker is te kijken naar de geëigende aanpak in een specifieke situatie, dan uitvoerig stil te staan bij definitiekwesties.

95. King e.a. 2009, p. 41-41.

96. King e.a. 2009, p. 42; Zehr 2015, p. 64.

97. Zehr 2015, p. 49. 
your organisational culture to become truly just' ${ }^{98}$ De keuze voor herstelrecht is evenwel goed te volgen. Herstelrecht heeft bepaalde eigenschappen die bij de andere Comprehensive pijlers minder expliciet aanwezig zijn en die nu juist goed passen in de context van medische schade. Het gaat om inclusiviteit en participatie. Ik licht dat hieronder nader toe.

\subsection{Een restorative aanpak is inclusief}

De eerste stap in een herstelgerichte aanpak is in kaart brengen wie er zijn benadeeld. Dat betekent dat een restorative aanpak gericht kan zijn op de belangen van de schadelijdende (patiënt) en de schadeveroorzakende partij (zorgverlener - die als 'second victim' eveneens tot de benadeelden kan worden gerekend), evenals de gemeenschap (de zorgaanbieder als derde slachtoffer, of familie en/of nabestaanden van de benadeelden). ${ }^{99}$ Juist in de gezondheidszorg is een inclusieve benadering van belang, nu we immers vaak niet te maken hebben met een dader-slachtofferperspectief, maar met een slachtoffertweede-slachtofferperspectief, en er tegelijkertijd moet worden nagedacht over kwaliteitsverbetering.

Een herstelgerichte reactie is ook een ontkokerde reactie. Het open karakter van herstelrecht en de inclusiviteit die dat meebrengt, biedt een theoretisch kader dat ziet op de hele afwikkeling van een incident, in plaats van te concentreren op de afwikkeling van het onderzoek, de klacht of het financiële plaatje. Dat sluit aan bij het idee dat verkokerde procedures strijdig zijn met de beleving en behoeften van patiënten, voor hen ingewikkeld en belastend zijn, dat de zorgplicht van een zorgaanbieder zich ook uitstrekt over het traject waarin de schade wordt afgewikkeld, en daarnaast dat patiëntveiligheid wordt gediend door een integrale aanpak van incidenten,

98. Dekker ziet procedural justice bijv. als een vorm van retributive justice; Dekker 2017, p. 1-9. Ook hij erkent echter dat het onderscheid niet altijd even scherp is en dat de verschillende vormen van rechtvaardigheid niet 'mutually exclusive' zijn, op p. 1.

99. Er bestaat discussie over de betekenis van 'gemeenschap'. Gemeenschap kan een plek zijn, maar vaker wordt gemeenschap in relationele zin bedoeld, zoals de microgemeenschappen die familie, vrienden, kerk en verenigingen uitmaken. P. McCold \& B. Wachtel, Community is not a place. A new look at community justice initiatives. Paper presented to the International Conference on Justice Without Violence: Views from Peacemaking Criminology and Restorative Justice, Albany, NY, 5-7 juni 1997. Zehr makt onderscheid tussen 'gemeenschap' en 'de maatschappij'. Naarmate een schadeveroorzakende gebeurtenis meer impact heeft op maatschappelijke thema's zoals mensenrechten, veiligheid en algemeen welzijn kan worden gezegd dat het conflict minder toebehoort aan de individuele belanghebbenden en dat de afwikkeling van de gebeurtenis meer in de sfeer van staatsverantwoordelijkheden komt te liggen. Zehr 2015, p. 38.

100. De zorgplicht van een zorgaanbieder in de afwikkeling van schade is opgenomen in aanbeveling 8 van de GOMA, en kwam aan de orde in het medisch tuchtrecht, zie Centraal Tuchtcollege 7 juli 2018, ECLI:NL:TGZCTG:2018:68; in het civiele recht: Hof Den Haag 30 mei 2017, ECLI:NL:GHDHA:2017:1409, waar de zaak op grond van art. 81 Wet RO door de Hoge Raad is afgedaan, HR 6 juli 2018 , ECLI:NL:HR:2018:1903, en is uitgebreid besproken in B.S. Laarman, De informatieplicht van een zorgaanbieder bij de afwikkeling van medische schade: over finale kwijting, geschilleninstanties en ongeïnformeerde patiënten, TVP 2018, afl. 3, p. 89-100. klachten en claims, ${ }^{100}$ omdat ook van klachten of minder ernstige gebeurtenissen geleerd kan worden. ${ }^{101}$

\subsection{Een restorative aanpak is participatief}

Uit onderzoek naar de ervaringen van patiënten blijkt dat zij de manier waarop openheid in de praktijk wordt gebracht niet altijd als patiëntgericht ervaren. Het gaat dan bijvoorbeeld om het maken van afspraken, de locatie van ingrijpende gesprekken of de betrokkenheid in onderzoek. ${ }^{102}$ Ervaringen van de ziekenhuizen die aan Leernetwerk OPEN deelnemen, bevestigen deze bevindingen: het gáát wel om de patiënt, maar de patiënt wordt nog niet altijd gevraagd naar wat hij of zij nu daadwerkelijk wil en hoe hij of zij het wil. Behoeften inventariseren gebeurt bijvoorbeeld wel in klachtenprocedures, maar verdwijnt veel sneller naar de achtergrond wanneer een procedure formaliseert, bijvoorbeeld bij een calamiteitenonderzoek of claimprocedure. Herstelrecht veronderstelt daarentegen het maatwerk dat door de professionals die wij in Leernetwerk OPEN spreken zo wordt voorgestaan. Dat betekent dat de daadwerkelijke behoeften van patiënten en zorgverleners op de eerste plek staan - in tegenstelling tot de behoeften zoals derden die veronderstellen, dan wel de formele rechten van benadeelden. Patiënten en zorgverleners kunnen immers heel andere behoeften hebben dan die het recht hun kan toebedelen. En sommige behoeften passen helemaal niet in de traditionele juridische hokjes.

\section{Ervaringen met herstelrecht}

\subsection{Herstelrecht in het Nederlandse strafprocesrecht}

Sinds 2010 zijn herstelgerichte benaderingen - eerst onder de term 'bemiddeling', inmiddels zuiverder geherformuleerd als 'herstelgerichte voorzieningen waaronder bemiddeling' - in het Wetboek van Strafvordering (Sv) opgenomen in artikel $51 \mathrm{~h}$, onder de titel 'Het slachtoffer'. In de praktijk wordt onderscheiden tussen herstelbemiddeling en mediation. ${ }^{103}$ Met herstelbemiddeling wordt gedoeld op alle vormen van begeleide ontmoetingen tussen de betrokkenen bij een strafbaar feit. ${ }^{104}$ Mediation is een vorm van herstelbemiddeling waarin het beoogde resultaat een juridische overeenkomst is

101. Zie o.m. B.S Laarman, T. Coppenhagen, R. Bouwman \& R.D. Friele, Ervaringen met de GOMA: ervaringen met deel A van de Gedragscode Openheid na medische incidenten; betere afwikkeling Medische Aansprakelijkheid (2010). Welke vragen spelen bij de implementatie van een open beleid in ziekenhuizen? Utrecht: Nivel 2018, p. 29.

102. Iedema e.a. 2011, 343(n/a), d4423; J. Moore \& M.M. Mello, Improving reconciliation following medical injury. A qualitative study of responses to patient safety incidents in New Zealand, BMJ 2017, p. 1-11, op p. 6.

103. I. Cleven, K.M.E. Lens \& A. Pemberton, De effecten, kosten en baten van herstelbemiddeling (2e rapport lange termijnresultaten), INTERVICT: Tilburg 2015, p. 1.

104. In Nederland wordt dader-slachtoffermediation o.a. verzorgd door Perspectief Herstelbemiddeling, een dochterorganisatie van Slachtofferhulp (www.perspectiefherstelbemiddeling.nl/). 
die van invloed kan zijn op het strafproces. ${ }^{105}$ Herstelrecht wordt met name toegepast bij lichte vergrijpen.

De positieve ervaringen die vanaf 2013 zijn opgedaan met vijf pilots over mediation in of naast het strafproces hebben ertoe geleid dat inmiddels bij alle rechtbanken een zaak kan worden aangehouden en voor mediation worden doorverwezen door de officier van justitie of de rechter. ${ }^{106,107}$ Wanneer een overeenkomst wordt gesloten, houdt de rechter daar in zijn of haar beslissing rekening mee. Ook de officier van justitie neemt een herstelovereenkomst in zijn of haar overwegingen mee. ${ }^{108}$ Dat kan er dus ook toe leiden dat strafrechtelijk optreden achterwege blijft, ${ }^{109}$ maar de strafeis, oplegging van straf of het besluit te seponeren blijft een beslissing van het Openbaar Ministerie en de rechter. ${ }^{110}$

In 2017 heeft een werkgroep van mensen van Stichting Herstelrecht Nederland en de Universiteit Maastricht een ontwerpwetsvoorstel aan de Tweede Kamer aangeboden strekkende tot de invoering van een zelfstandige titel 'Herstelrechtvoorzieningen'. ${ }^{11}$ Ook in dit ontwerpwetsvoorstel zijn herstelrechtvoorzieningen een aanvulling op het strafrecht en geen vervanging. In het wetsvoorstel wordt gepleit voor een steviger verankering van herstelrechtvoorzieningen in het Sv, waaronder bemiddeling, mediation en de herstelconferentie. ${ }^{112}$ Het verschilt per type herstelrechtvoorziening of, en in welke mate, de uitkomst daarvan invloed kan hebben op het strafproces. Dat heeft vervolgens invloed op de waarborgen waarmee de herstelrechtvoorziening moet zijn omkleed. ${ }^{113}$ Het wetsvoorstel werkt met name de mogelijkheid tot mediation uit.

\subsection{Onderzoek naar het effect van herstelrecht}

Het WODC deed onderzoek naar de ervaringen met mediation in of naast het strafproces in de pilotfase. Dat onderzoek wijst uit dat slachtoffers mediation positief ervaren. $\mathrm{Zij}$ waardeerden de respectvolle behandeling, de mogelijkheid om inbreng te geven, dat er voldoende tijd was ingeruimd, en dat

105. J. Claessen, Herstelrechtvoorzieningen in het (nieuwe) Wetboek van Strafvordering: geen luxe maar noodzaak met het oog op de realisering van een humane rechtspleging, Platform Modernisering Strafvordering, 2018, nr. 1, par. 2.1

106. A. Wolthuis \& M. Berger, Herstelrecht in jeugdstrafzaken in Nederland, waar staan we?, Tijdschrift jeugdrecht in de praktijk 2017, afl. 3, 2017, p. 29.

107. Zie noot 105 .

108. J. Blad, Advocatuur in strafrecht en herstelrecht: een verkenning van de verschillen, TvH 2016, afl. 2, p. 10-26, op p. 16.

109. J. Claessen \& G. Zeles, Bemiddeling in strafzaken in Maastricht: de eerste onderzoeksresultaten, NJB 2013/1604, onder 1.

110. Wolthuis \& Berger 2017, p. 29.

111. J. Blad, J.A.A.C. Claessen, G.J. Slump, A. van Hoek \& Th. de Roos, Voorstel van Wet strekkende tot de invoering van een herstelgerichte afdoening via bemiddeling in strafzaken in het Wetboek van Strafvordering, inclusief memorie van toelichting, Nijmegen: Wolf Legal Publishers 2017.

112. J. Claessen, 2018, par. 2.2 .

113. Claessen 2018, par. 2.2-2.6. Indien de herstelrechtvoorziening invloed kan hebben op het strafproces, moet worden voldaan aan de kwaliteitswaarborgen zoals die gelden voor mediation. het traject vertrouwelijk was. ${ }^{114}$ Daar staat tegenover dat slachtoffers ook aangaven teleurgesteld te zijn in de opstelling van de wederpartij en dat de impact op traumatische stress, angst en woede bij het slachtoffer klein was. Bij daders was het effect op spijt, schuld en trots bij de dader eveneens klein. ${ }^{115}$ Voor deelnemers aan het WODC-onderzoek was het voorkomen van recidive wel een belangrijke reden om aan herstelbemiddeling mee te werken, maar slechts een minderheid van hen had de indruk dat de mediation daar ook daadwerkelijk aan had bijgedragen. ${ }^{116}$

Wolthuis en Berger bespreken voorbeelden van zaken waarin in Nederland mediation is uitgevoerd. Slachtoffers haalden troost uit gesprekken en werden minder angstig, daders werden zich bewust van de impact van de gebeurtenissen, ieders bijdrage aan het gebeurde werd geanalyseerd, er werd verantwoordelijkheid genomen en partijen bleken in staat om het geschonden vertrouwen te herstellen en gevoelens van onveiligheid te verminderen. ${ }^{117}$ Of de mediations ook bijdroegen aan de publieke dimensie van herstelrecht, zoals voorkomen dat daders opnieuw in de fout gaan, wordt in deze voorbeelden niet vermeld. Een mogelijke reden daarvoor kan zijn dat de publieke dimensie van herstelrecht bij mediation geen expliciete plek heeft. ${ }^{118}$ Mediation vindt immers plaats tussen de dader en het slachtoffer, ${ }^{119}$ reden voor Claessen om te pleiten voor een bredere inzet van herstelconferenties. ${ }^{120}$

De goede ervaringen in Nederland sluiten aan bij bevindingen uit internationaal wetenschappelijk onderzoek: slachtoffers en daders zijn tevredener met herstelgerichte processen dan met een strafproces. Uit een synthese van 22 studies door Latimer e.a. blijkt dat procedures vaak tot overeenkomsten leiden die strekken tot vergoeding van de schade van het slachtoffer. Deze overeenkomsten worden in de regel goed nagekomen. Ook rapporteren Latimer e.a. een reductie in recidive. ${ }^{121}$ In een literatuurreview door Sherman e.a. komt naar voren dat slachtoffers in herstelgerichte processen over het algemeen tevredener zijn dan slachtoffers in strafprocessen, onder de voorwaarden dat het herstelproces verloopt zoals afgesproken

114. I. Cleven, K.M.E. Lens \& A. Pemberton, 2016, p. 13.

115. Cleven, Lens \& Pemberton 2016, p. 13-14.

116. Cleven, Lens \& Pemberton 2016, p. 13.

117. Wolthuis \& Berger 2017, p. 29, onder verwijzing naar Infoblad 1, Mediation in Strafzaken, 05/2017.

118. Of omdat recidive op korte termijn natuurlijk lastig te meten is. Overigens zien de WODC-onderzoekers wel een groot potentieel voor het voorkomen van recidive, al doen zij deze uitspraak op basis van literatuuronderzoek en niet op basis van de behaalde pilotresultaten. Cleven, Lens \& Pemberton 2016, p. 17.

119. Dat geldt eens te meer omdat bij mediation vertrouwelijkheid wordt afgesproken. Brenninkmeijer e.a. 2017.

120. J. Claessen, Herstelrechtvoorzieningen in het (nieuwe) Wetboek van Strafvordering: geen luxe maar noodzaak met het oog op de realisering van een humane rechtspleging, Tijdschrift Modernisering Strafvordering (1) 2019, afl. 2, par. 3 .

121. J. Latimer, C. Dowden \& D. Muise, The effectiveness of restorative justice practices: A meta-analysis, The Prison Journal (85) 2005, afl. 2, p. 127-144, op p. 136-138. 
en dat de dader zich aan de tijdens de bijeenkomst gemaakte afspraken houdt. ${ }^{122}$

Een redelijk recente literatuurreview is uitgevoerd door Strang e.a. in 2013. ${ }^{123} \mathrm{Zij}$ selecteerden tien studies die het effect meten van herstelrecht op recidive en impact op het slachtoffer. Met betrekking tot het slachtoffer vonden zij een klein (positief) effect op materiële compensatie en significante verschillen in emotioneel herstel, zoals ervaren veiligheid en het krijgen van een oprecht excuus. De auteurs vonden grote verschillen tussen slachtoffers in rechtbankprocedures en slachtoffers in herstelgerichte processen, waarbij de laatste categorie slachtoffers (veel) vaker een excuus kreeg van de dader (een studie rapporteert $72 \%$ in een conference versus $19 \%$ in de rechtbank, een andere $96 \%$ versus $7 \%$; tot slot $100 \%$ versus $14 \%)$. Excuses werden ook vaker als oprecht ervaren. ${ }^{124}$

De geanalyseerde studies meten de tevredenheid van slachtoffers op verschillende wijzen, maar alle rapporteren een grotere tevredenheid met herstelgerichte processen dan met rechtbankprocedures, bijvoorbeeld in ervaren eerlijkheid. Ook concluderen de auteurs dat herstelrecht kan bijdragen aan het verminderen van wraakgevoelens. Tot slot rapporteren Strang e.a. dat slachtoffers in herstelgerichte procedures minder vaak PTSS-klachten hebben. ${ }^{125}$ In een overzicht van empirisch onderzoek op het gebied van herstelrecht zetten Rietman e.a. de resultaten nog eens kort op een rijtje. ${ }^{126}$

Overigens is het natuurlijk niet alles goud wat er blinkt. Latimer e.a. benoemen ook een kleine minderheid waarvoor herstelrecht een negatieve ervaring was, en die hun situatie mogelijk zelfs verslechterd heeft. ${ }^{127}$ Voorts spelen er waarschijnlijk wel enige problemen met betrekking tot bias. Dat geldt bijvoorbeeld wanneer zaken worden geselecteerd op hun 'geschiktheid' voor een herstelgericht proces, of wanneer het nemen van verantwoordelijkheid een voorwaarde is voor deelname. ${ }^{128}$ Ook voor de Nederlandse strafrechtpraktijk geldt dat de dader verantwoordelijkheid moet nemen voor zijn of haar aandeel in de gebeurtenis om voor herstelbemiddeling in aanmerking te komen. Dat kan de ervaring van slachtoffers en daders kleuren.

122. L. Sherman \& W. Strang, m.m.v. H. Barnes e.a., Restorative justice: The evidence, Londen: The Smith Institute 2007, in hoofdstuk 9 'Reducing harm to victims' en hoofdstuk 13 'Other effects on crime'.

123. H. Strang, L.W. Sherman, E.M. Wilson, D. Woods \& B. Ariel, Restorative Justice Conferencing (RJC) using face-to-face meetings of offenders and victims. Effect on offender recidivism and victim satisfaction. A systematic review, Campbell Systematic Reviews 2013/12.

124. In het WODC-onderzoek rapporteert een derde van de deelnemende slachtoffers een oprechte spijtbetuiging te hebben gekregen. 'Slechts', in de woorden van de onderzoekers. Het percentage wordt echter niet afgezet tegen het aantal oprechte spijtbetuigingen in het reguliere strafprocesrecht.

125. Strang e.a. 2013 , p. 37-44.

126. M. Rietman e.a., Effectiveness of restorative justice practices. An overview of empirical research on restorative justice practices in Europe, via www.euforumrj.org/publications/research-reports/.

127. Latimer e.a. 2005 , p. 62.

128. Zie bijv. Strang e.a. 2013, p. 13.

\section{De betekenis van herstelrecht voor de afwikkeling van (medische) schade}

\subsection{Herstelrecht als nieuw perspectief op de afwikkeling van schade}

Het herstelrecht heeft veel te bieden wanneer het gaat om een heilzamer manier om schadeclaims af te wikkelen. Op welke manier kunnen herstelrechtelijke beginselen daarbij helpen? Om te beginnen zal herstelrecht geen vervanging zijn, maar een nieuw perspectief. Het civiele recht kenmerkt zich van oudsher sowieso al door een cultuur van overleg en schikken in plaats van procederen, ${ }^{129}$ veel meer dan dat in andere rechtsgebieden het geval is. Blad noemt herstelgerichte procedures in het strafrecht zelfs een 'civilisering' van het strafprocesrecht, al ziet dat vooral op het gebruik om herstelbemiddeling af te sluiten met een overeenkomst. ${ }^{130} \mathrm{Er}$ zijn binnen de huidige rechtspraktijk dan ook al aangrijpingspunten te vinden waar een herstelgerichte aanpak aan kan worden opgehangen. In deze paragraaf wordt aansluiting gezocht bij de verplichtingen zoals die gelden voor een adequate reactie op klachten en claims zoals neergelegd in de Wkkgz, de aanbevelingen omtrent schadeafwikkeling zoals neergelegd in de Gedragscode Behandeling Letselschade (GBL), de ervaringen die reeds worden opgedaan met, wat wordt genoemd, herstelgerichte schadeafwikkeling of herstelgerichte dienstverlening, en tot slot de aandacht die er bestaat voor het aanbieden van excuses.

\subsection{De Wkkgz als een kader voor herstelrecht}

In de Wkkgz wordt geen onderscheid gemaakt tussen een klacht met een financiële component (een 'claim') en een klacht zonder een financiële component, de zogenaamde 'samenloop tussen klacht en claim'. Hoe zit dat? Zorgaanbieders - waarmee hier overigens wederom nadrukkelijk de instelling wordt bedoeld - zijn op grond van artikel $16 \mathrm{Wkkgz}$ verplicht klachten zelf zorgvuldig te onderzoeken, maar de Wkkgz legt niet uit wat er onder een 'klacht' moet worden verstaan. In de parlementaire geschiedenis van de Wkkgz heeft de minister echter uitdrukkelijk uitgemaakt dat de wet zowel ziet op klachten met als op klachten zonder financiële component. ${ }^{131}$ Dat betekent dus dat in beginsel alle medische schadeclaims onder het regime van de Wkkgz vallen. ${ }^{132}$ Wie over de consequenties hiervan doordenkt, kan alleen maar concluderen dat voor de afhandeling van medische claims niet alleen de procedurele voorwaarden voor adequate klachtbehandeling gelden, maar dat voortaan ook de uitgangspunten van het klachtrecht in acht moeten worden genomen.

129. Overigens is ook in Regel 5 van de Gedragsregels Advocatuur opgenomen dat een minnelijke oplossing de voorkeur geniet boven procederen; http://regelgeving.advocatenorde.nl/content/gedragsregels-advocatuur.

130. J.R. Blad, Herstelrecht en civilisering van de strafrechtspleging, in: M-C. Foblets, M. Hildebrandt \& J. Steenbergen (red.), Liber amicorum René Foqué, Gent/Den Haag: Larcier/Boom Juridische uitgevers 2012, p. 169-188.

131. Kamerstukken I 2014/15, 32402, O, p. 3 (NV).

132. W.R. Kastelein, De Wkkgz is er: een nieuwe klachten- en claimregeling in de zorg!, TvGR 2016, afl. 2, p. 62-70, op p. 67. 
In het kader van de afwikkeling van claims is dan met name relevant dat het klachtrecht erop is gericht machtsongelijkheid te compenseren. ${ }^{133}$ In het klachtrecht is een patiënt de zwakkere partij die wordt geholpen bij het vinden van een oplossing voor zijn of haar onvrede. Dat wordt meestal concreet ingevuld door de gratis bijstand van een daartoe aangestelde klachtenfunctionaris. Klachtrecht is daarom niet reactief, maar proactief, en niet gericht op tegenspraak, maar juist oplossingsgericht. De samenloop tussen klacht en claim betekent dan ook niet alleen dat de zorgaanbieder beide soorten klachten inhoudelijk in behandeling moet nemen, maar dat hij dit, conform de uitgangspunten van het klachtrecht, ook proactief en oplossingsgericht zou moeten doen. Proactief schade afwikkelen betekent concreet dat de zorgaanbieder niet kan afwachten tot een patiënt met een goed onderbouwde claim komt aanzetten, maar zelf moet onderzoeken hoe samen met de patiënt tot een oplossing van het probleem kan worden gekomen.

Hier ligt het aangrijpingspunt voor een herstelgerichte aanpak in de afwikkeling van claims. Kenmerkend voor het herstelrecht is immers dat er na een gebeurtenis in kaart wordt gebracht wie er door de gebeurtenis zijn geraakt, welke behoeften deze personen hebben, en hoe daaraan tegemoet kan worden gekomen. In het kader van een incident in de gezondheidszorg zal daarom afhankelijk van de fase waarin een gebeurtenis wordt 'ontdekt', verschillen wie daarbij betrokken worden en wat hun behoeften zijn. Wanneer direct duidelijk is dat een gebeurtenis schade heeft veroorzaakt, brengt een consequent doorgevoerd herstel- of klachtrechtelijk beleid een plicht tot proactieve vergoeding van schade mee. Dat zou betekenen dat patiënten helemaal niet meer zouden hoeven 'claimen', maar dat een schadeveroorzakende gebeurtenis de verplichting doet ontstaan om uit eigen beweging onderzoek te doen en schadevergoeding aan te bieden. Vertrouwde aansprakelijkheidsrechtelijke noties als stelplicht en bewijslast zijn niet langer van toepassing (stelplicht) of komen in een heel ander licht te staan (bewijslast).

\subsection{Een behandelplan letselschade}

Ook wanneer proactief schade afwikkelen niet voor de hand ligt, bijvoorbeeld vanwege de simpele reden dat de zorgaanbieder pas van het ontstaan van de schade op de hoogte raakt wanneer de patiënt hem of haar daarover informeert, noopt de Wkkgz tot een oplossingsgerichte - of inderdaad, herstelgerichte - afwikkeling van de claim. De wens om personenschade sneller, duidelijker en harmonieuzer af te wikkelen was eerst in 2006 en in een herziene versie in 2012 aanleiding voor het schrijven van de GBL. De GBL bevat tien gedragsregels voor verzekeraars, slachtoffers en belangenbehartigers. ${ }^{134}$

133. Over de consequenties van deze verplichting is uitgebreid stilgestaan in een eerdere bijdrage in dit tijdschrift. Zie Laarman \& Akkermans 2017. Voor een analyse van de eigen aard van het klachtrecht zie p. 59-60 van deze bijdrage.

134. Zie https://deletselschaderaad.nl/stichting-letselschade-raad/gedrags codes/gbl/.
In de GBL wordt aanbevolen tot het opstellen van een 'behandelplan letselschade' (beginsel 7). Dat is een plan van aanpak dat aan het begin van het afwikkelingstraject in samenspraak tussen de schadelijdende partij en diens belangenbehartiger en de verzekeraar wordt opgesteld. In het behandelplan worden de stappen benoemd die moeten worden gezet om tot afwikkeling te komen, het bevat afspraken over de verdeling van verantwoordelijkheden en de termijnen waarbinnen men van plan is een en ander af te ronden. ${ }^{135}$ De schadelijdende partij is in deze aanpak niet passief, maar participeert in de besluitvorming over zijn of haar eigen zaak.

Voor zover bekend wordt van deze mogelijkheid op dit moment nog geen gebruik gemaakt, maar dat wil niet zeggen dat het belang van samen optrekken in de afwikkeling van schade niet wordt ingezien. Op een recent symposium van Centramed ${ }^{136}$ werden door aanwezigen uit de letselschadebranche en de ziekenhuiswereld plannen geopperd die uitdrukkelijk in deze richting wezen: snel samen om de tafel, goede afspraken maken en elkaar op de hoogte houden van de voortgang. Het zou mooi zijn als deze plannen opvolging kregen. ${ }^{137}$ Hoe raar dat namelijk ook klinkt, de persoon die bij de verzekeraar de schade moet beoordelen, heeft de patiënt in de meeste gevallen nog nooit gezien. Bij verzekeraars is het werk verdeeld tussen een 'buitendienst', die bij de patiënt op bezoek gaat en in kaart brengt wat de schade is, en een 'binnendienst', die schades beoordeelt en schriftelijk afhandelt. Ervaringen met mediation wijzen uit dat juist veel kan worden opgelost wanneer alle partijen aan tafel zitten en elkaars verhaal aanhoren:

'Vaak ziet het slachtoffer degene die voor de verzekeraar de zaak "binnen" behandelt voor de eerste keer. Die ontmoeting genereert een gevoel van opluchting aan beide kanten. Als partijen de tijd nemen om uitgebreid naar elkaars ver-

135. A.J. Akkermans \& L. Hulst, De niet-financiële impact van schadetoebrenging en hoe daaraan tegemoet te komen: over excuses, actieve schadeafwikkeling en procedurele rechtvaardigheid, TVP 2014, afl. 4, p. 102-110, op p. 109-110.

136. Centramed organiseerde ter ere van het 25 -jarig bestaan het symposium 'Ketenkracht' op 20 juni 2019. Centraal stond de vraag hoe de afwikkeling van letselschade kan worden versneld. Op het symposium waren belangenbehartigers, afgevaardigden uit ziekenhuizen en medewerkers van Centramed en MediRisk aanwezig, die onder begeleiding met elkaar in gesprek gingen om elkaar beter te leren kennen en tot nieuwe inzichten te komen.

137. Een vergelijking kan worden gemaakt met wat sociale wetenschappers het 'unidentified lives phenomenon' noemen (W.E. Parmet, Valuing the unidentified: The potential of public health law, Jurimetrics (53) 2013 , p. 255-277, op p. 256-257); het verschijnsel dat mensen liever geld uitgeven aan de levens van mensen die ze kennen dan aan abstracte en anonieme levens. Econoom Thomas Shelling legt dit uit aan de hand van een voorbeeld: 'Let a six-year old girl with brown hair need thousands of dollars for an operation that will prolong her life until Christmas, and the post office will be swamped with nickels and dimes to save her. But let it be reported that without sales tax the hospital facilities of Massachusetts will deteriorate and cause a barely perceptible increase in preventable deaths - not many will drop a tear or reach for their checkbooks.' Geciteerd in R.H. Thaler, Misbehaving: The making of behavioral economics, Londen: Penguin Books 2016. 
haal te luisteren, wordt vaak al veel tussen hen opgeklaard. Het gaat dan niet alleen om het verhaal van het slachtoffer (dat ligt voor de hand), maar ook om dat van de behandelaar. Hij kan beter uitleggen wat zijn rol is geweest in het proces, hoe hij tot bepaalde inzichten is gekomen, wat daarbij de rol is geweest van de medisch adviseur, aan welke regels hij is gebonden, aan wie hij verantwoording moet afleggen en op welke manier.' ${ }^{\text {'38 }}$

Meer persoonlijk contact in de afwikkeling van schadeclaims lijkt ook essentieel om een echte herstelgerichte afwikkeling mogelijk te maken. Dat hoeft helemaal niet te leiden tot het vaker toewijzen van claims, maar kan er ook aan bijdragen dat een afwijzing op een patiëntvriendelijker manier wordt ingestoken.

Persoonlijk contact kan ook de positie van de zorgverlener ten goede komen. Patiënten (en hun belangenbehartigers) zijn zich er waarschijnlijk niet altijd van bewust welke impact een medisch incident ook op de zorgverlener kan hebben. Van de betrokken patiënt kan dat begrip ook niet zomaar worden verwacht. Van de belangenbehartiger daarentegen mag men wél verwachten dat die zich in zoverre redelijk opstelt dat hij of zij de zorgverlener geen nodeloze schade berokkent. Dat kan concreet inhouden dat de belangenbehartiger onredelijke verwachtingen ten opzichte van de zorgverlener tempert, en dat hij of zij nadenkt over de toon van de communicatie en de wijze van procesvoering, zoals het dreigen met een tuchtklacht.

\subsection{Zelfregelende ziekenhuizen}

De samenloop tussen klacht en claim heeft nog een ander (mogelijk) voordeel, namelijk dat deze de betrokkenheid van zorgaanbieders (hier wederom nadrukkelijk te onderscheiden van de individuele zorgverlener) in de afwikkeling van schade faciliteert. In de rolverdeling zoals wij die gewend zijn, behandelen zorgaanbieders zelf klachten (dus zonder financiële component), maar wordt een patiënt naar de verzekeraar doorverwezen wanneer duidelijk wordt dat een patiënt ook een schadevergoeding wenst. De schadebehandelaar van de verzekeraar beoordeelt de claim vervolgens op zijn juridische merites. In dit proces is de zorgaanbieder vaak niet meer in beeld, maar heeft de patiënt voornamelijk te maken met de schadebehandelaar van de verzekeraar. De afgelopen jaren - ook al voor de invoering van de Wkkgz - zien we in de ziekenhuissector steeds vaker voorkomen dat ziekenhuizen de afwikkeling van claims onderbrengen bij hun juridische afdeling, zogenaamde 'zelfregelende ziekenhuizen'. 139

Een herstelgerichte aanpak brengt in kaart welke behoeften het voorval heeft doen ontstaan en hoe daaraan tegemoet kan

138. G.M. van Wassenaer, Mediation: dé oplossing bij letselschade?, VR 2016, afl. 2, p. 49-56, op p. 18.

139. Centramed en MediRisk hanteren in hun verzekeringsvoorwaarden een bepaald eigen risico waarvan de hoogte met de verzekerde kan worden afgesproken en waaronder de verzekerde de schade 'zelf regelt'. De verzekeraar komt pas in beeld wanneer de schade het eigen risico overstijgt. worden gekomen. Uit de praktijk van de zelfregelende ziekenhuizen uit Leernetwerk OPEN is bekend dat zij sneller overgaan tot coulanceregelingen. Ook is bekend dat veel klachtenfunctionarissen een 'potje' beschikbaar hebben waaruit zij proactief activiteiten vergoeden. Dat potje kan worden aangesproken wanneer strikt juridisch gezien geen aansprakelijkheid kan worden vastgesteld maar men wel van mening is dat de gang van zaken beter had gekund, of wanneer er wel aansprakelijkheid kan worden vastgesteld en de patiënt met heel concrete maatregelen verder kan worden geholpen. Bekende voorbeelden zijn de aanschaf van een nieuwe rolstoel, aanpassingen in huis of de vergoeding van een vakantie met het gezin.

\subsection{Herstelgericht schade afwikkelen en herstelgerichte dienstverlening}

Deze aanpak sluit aan bij de pogingen van professionals in de letselschadebranche om te komen tot, wat wordt genoemd, herstelgerichte schadeafwikkeling. Dan gaat de aandacht niet uitsluitend uit naar financiële genoegdoening ('een zak met geld'), maar eveneens naar de manieren waarop iemand sociaal, psychisch, medisch en praktisch kan worden geholpen. ${ }^{140}$ Herstelgerichte schadeafwikkeling kan inhouden dat op een hele andere manier tot een overeenkomst wordt gekomen. Sommige professionals doen vóór het ondernemen van juridische stappen eerst een laatste poging om met de andere partij in gesprek te komen, ${ }^{141}$ andere doen positieve ervaringen op met mediation, ${ }^{142}$ al wordt mediation nu nog met name in de arbeidsrechtpraktijk en het familierecht toegepast. ${ }^{143}$

Zoals de ziekenhuizen hun 'potje' kunnen aanspreken voor concrete aanpassingen in de situatie van de schadelijdende patiënt, kan herstelgericht werken ook in de letselschadebranche betekenen dat het schadebegrip zelf een andere invulling krijgt. Zo bieden sommige letselschadekantoren een herstelcoach aan. Een herstelcoach regelt niets vóór het slachtoffer, maar helpt een letselschadeslachtoffer om de autonomie terug te krijgen door samen te kijken naar activiteiten waarvan het slachtoffer denkt dat die bijdragen aan herstel. De herstelcoach vraagt vervolgens bij betrokken partijen om financiering van die activiteit. ${ }^{144}$ Door onder anderen Van Dijck en Hartlief is dit gedachtegoed doorgetrokken naar het schadebegrip zelf, dat in plaats van terugkijkend toekomstgericht zou moeten worden, waarbij de schadevergoeding wordt vastgesteld niet op basis van wat zonder ongeval of fout had kunnen zijn, maar aan de hand van wat iemand nodig heeft om er in de ont-

140. P.J.M. van Steen, Pleidooi voor de inzet van herstelcoaches, TLP 2017, afl. 3, p. 17.

141. Bij letselschadebureau Ottenschot wordt voor het ondernemen van juridische stappen eerst een poging tot bemiddeling gedaan. Zie hierover B.S. Laarman, Uit de ring en om de tafel: over openheid na medische incidenten en het belang van de dialoog, TLP 2016, afl. 3, p. 38-41.

142. Van Wassenaer 2016.

143. L. Charlier, Mediation in letselschade blijft ten onrechte achter, L\&S 2018, afl. 3, p. 16-24, cijfers op p. 20-21.

144. Van Steen 2017, p. 17; F.Th. Peters \& E.A. van den Berg-Bakker, Herstelcoaching bij niet-objectiveerbare klachten, TLP 2014, afl. 1, p. 10-14. 
stane situatie het beste van te maken. ${ }^{145}$ Iets vergelijkbaars wordt in sommige ziekenhuizen opgepakt in de pilot Casemanagement, die wordt uitgevoerd door Fonds Slachtofferhulp. Casemanagers zijn onafhankelijke personen die ondersteuning bieden op praktisch, juridisch en psychosociaal vlak. $^{146}$

\subsection{Het belang van excuses}

In het herstelrecht ligt een nadrukkelijke focus op immateriële behoeften van rechtzoekenden. Een herstelgerichte aanpak is geslaagd wanneer de 'dader' verantwoordelijkheid neemt voor wat er is gebeurd en daarvoor zijn of haar excuses aanbiedt. Een laatste hypothese is daarom dat zelf regelen een herstelgerichte aanpak goed kan faciliteren, omdat patiënten vaak behoeften hebben waar de verzekeraar maar moeilijk in kan voorzien. ${ }^{147}$ Het gaat dan bijvoorbeeld om het verschaffen van meer openheid, het krijgen van erkenning voor wat er is gebeurd of het maken van excuses. ${ }^{148,} 149$ Dat excuses belangrijk zijn, blijkt ook uit onderzoek naar de afwikkeling van claims in andere sectoren, zoals het verkeersrecht. Excuses kunnen bijdragen aan een sneller psychisch en fysiek herstel. Het aanbieden van excuses kan ook een positieve uitwerking hebben op het verloop van de schadeafwikkeling, omdat excuses negatieve emoties zoals boosheid, de neiging tot vergelding en de ingeschatte kans op herhaling van het schade-

145. G. van Dijck, Naar een nieuw schadevereiste in het aansprakelijkheidsrecht: over herstel binnen de ontstane toestand en een toekomstgerichte maatstaf, NJB 2016, afl. 23, p. 1608-1616. T. Hartlief, Personenschade; toekomstgerichte vergoeding en herstel van keuzevrijheid, TLP 2017, afl. 2 , art. 47.

146. Zie https://fondsslachtofferhulp.nl/project/pilot-casemanagementmedische-incidenten/.

147. Naar de ervaringen met 'zelf regelen' is in Nederland nog geen onderzoek gedaan. In de Verenigde Staten zijn die studies er wel, maar die zien voornamelijk op de mogelijke verhoging van de schadelast. T.H. Gallagher, M.M. Mello, W.M. Sage e.a., Can communication-and-resolution programs achieve their potential? Five key questions, Health Affairs (37) 2018, afl. 11, p. 1845-1852, op p. 1848. Die invloed lijkt er overigens niet te zijn. A. Kachalia, K. Sands, M. Van Niel e.a., Effects of a communication-and-resolution program on hospitals' malpractice claims and costs, Health Affairs (37) 2018, afl. 11, p. 1836-1844.

148. Het zo veel mogelijk door zorgaanbieders zelf afwikkelen van schadeclaims is ook een van de centrale aanbevelingen in het VU-onderzoek naar opvang en schadeafwikkeling bij onbedoelde gevolgen van medisch handelen uit 2013, Smeehuijzen e.a. 2013. Ook internationaal wordt ervaring opgedaan met het zelf regelen van schade. Vooruitstrevende Amerikaanse ziekenhuizen werken met early settlement programmes. In genoemd VU-rapport wordt een overzicht van literatuur gegeven. Ook Akkermans en ik beschrijven een dergelijk werkproces kort in Laarman \& Akkermans 2017, op p. 65, maar wie hier meer over wil weten, wordt van harte aanbevolen de vele publicaties van o.m. Michelle Mello (m.n. M.M. Mello, R.C. Boothman, T. McDonald e.a., Communication-andresolution programs: The challenges and lessons learned from six early adopters, Health Affairs (33) 2014, afl. 1, p. 20-29) en Richard Boothman (m.n. bijv. R.C. Boothman, A.C. Blackwell, D.A. Campbell, Jr., E. Commiskey \& S. Anderson, A better approach to medical malpractice claims? The University of Michigan experience, Journal of Life and Health Sciences (2) 2009, afl. 2, p. 125-159) te raadplegen.

149. Het lijkt erop, zo blijkt uit par. 9 van deze bijdrage, dat herstelrecht het maken van excuses bevordert, en dat deze excuses door slachtoffers ook als oprecht worden ervaren, al zijn er ook tegengeluiden, zie bijv. K. Daly, The limits of restorative justice, in: Handbook of restorative justice: A global perspective, New York: Routledge 2006, p. 134-143. veroorzakende gedrag verminderen. Excuses dragen ook bij aan een constructieve en verzoenende opstelling naar de schadeveroorzaker. ${ }^{150}$ Zoals echter vaak het geval is in de afwikkeling van schade is het moeilijker excuses maken wanneer er tussen partijen geen persoonlijk contact bestaat. Daarom wordt door de Vrije Universiteit Amsterdam en Moondocs samengewerkt in het project CONTACT, dat persoonlijk contact tussen veroorzakers en slachtoffers van ernstige verkeersongevallen bevordert met behulp van een website waar informatie, voorlichting, podcasts van gesprekken tussen veroorzakers en slachtoffers van verkeersongevallen en onderzoek beschikbaar zijn. In de context van medische incidenten wordt aan een vergelijkbaar project gewerkt, genaamd 'Goed Opgelost'. Ook hier is het beoogde eindproduct een website die patiënten handvatten biedt om een klacht, claim of incident op een constructieve manier aan de orde te stellen.

\section{Enkele kanttekeningen}

Er zijn schrijvers die zo hun vraagtekens plaatsen bij het herstelrecht. Omwille van de ruimte beperk ik mij tot die bezwaren die relevant zijn in het kader van de afwikkeling van schade. Het betreft de mate van vrijwilligheid, het risico van willekeur en daaraan gerelateerd, de vraag of er zaken zijn die te zwaar of te complex zijn om in herstelrecht op te pakken. Aan het slot van deze paragraaf wordt kort stilgestaan bij de betekenis van herstelrecht voor de opleiding van juridische professionals.

\subsection{Vrijwilligheid}

Herstelrecht vereist vrijwillige en actieve participatie van de patiënt, de zorgaanbieder en/of de zorgverlener. Van participatie is in het (informele) klachtentraject waarschijnlijk in de meeste gevallen wel sprake door de nadruk op klachtbemiddeling. Maar in procedures die sterker geformaliseerd zijn, zoals de afhandeling van claims, verdwijnen de behoeften van de direct belanghebbenden, de patiënt en de zorgverlener, vaak uit beeld en is van echte participatie vaak weinig sprake meer. Wanneer de aangesproken persoon niet wil meewerken, ontkent wat er is gebeurd of de impact daarvan miskent, kan herstelrecht traumatiserend zijn. ${ }^{151}$

In het strafrecht wordt aan problemen met betrekking tot participatie tegemoetgekomen door als voorwaarde te stellen dat de dader bekent en verantwoordelijkheid neemt voor wat er is gebeurd. Dat kan een probleem opleveren met betrekking tot vrijwilligheid. Voor Geeraets zijn die problemen zo fundamenteel dat hij vrijwilligheid in het herstelrecht zelfs een fictie noemt: de dreiging van een strafproces zou de vrije keuze zozeer beperken dat daarvan helemaal geen sprake meer kan zijn. Aan slachtofferzijde is in de visie van Geeraets eveneens sprake van drang. Het verzoek om mee te werken aan herstelrecht is een beroep op compassie, waardoor slachtoffers zich

150. Akkermans \& Hulst 2014.

151. Z.D. Gabbay, Justifying Restorative Justice: A Theoretical Justification fort he Use of Restorative Justice Practices, Journal of Dispute Resolution (2) 2005, article 4, p. 360; Sherman \& Strang 2007, p. 62. 
mogelijk niet vrij voelen om te weigeren. ${ }^{152}$ Die zorg is niet uit de lucht gegrepen: in het WODC-rapport betreffende de pilots in herstelbemiddeling wordt benoemd dat soms druk wordt uitgeoefend op daders en/of slachtoffers om aan herstelbemiddeling mee te werken, al was vrijwilligheid in de meeste pilots volgens deelnemers goed geborgd. ${ }^{153}$

Hoe moet dat in het (medische) aansprakelijkheidsrecht, waar nu juist de erkenning van aansprakelijkheid zo vaak het pijnpunt is in de afwikkeling van de schade? De cynicus kan zeggen dat de zorgverlener in het traditionele aansprakelijkheidsrecht 'beter' af is, waar immers de patiënt nog wel stelplicht en bewijslast draagt en de zorgverlener/zorgaanbieder er met zwijgend achteroverleunen nog immer goed vanaf kan komen. ${ }^{154}$ Ten tweede kan worden gezegd dat herstelrecht, met de dreiging van langdurige, formele en belastende procedures op de achtergrond, op verholen wijze de aangesproken partij dwingt tot het nemen van verantwoordelijkheid waar die er misschien niet is. En er zijn ook patiënten die in deze fase niet meer zitten te wachten op een goed gesprek.

Dit zijn reële bezwaren waarmee rekening moet worden gehouden. Daarom wordt herstelrecht nadrukkelijk aangedragen als een nieuw perspectief dat kan helpen op een heilzamer manier aan schadeafwikkeling vorm te geven, niet als een vervanging. Het goede nieuws is dat herstelrecht er precies op is gericht achteroverleunen actief tegen te gaan ${ }^{155}$ en daarbij het risico op hervictimisatie van zowel patiënt als zorgverlener te minimaliseren door het bevorderen van wederzijds begrip. Braithwaite zegt hierover: '(...) the test is not whether human capabilities actually are developed to the full as a result of a restorative justice process, but whether a restorative process leads us closer to this ideal rather than leading us away from it, and closer than non-restorative alternatives.' ${ }^{\text {156 }} \mathrm{Of}$, in de woorden van Van Stokkom: '(...) enkele (potentiële) ondeugden van het herstelrecht (zijn) genoemd. Echter, die ondeugden vallen ongetwijfeld in het niet bij die van een louter vergeldend recht.' ${ }^{157}$ Zo bezien lijkt herstelrecht kansen te bieden die het klassieke stelsel niet in de aanbieding heeft.

\subsection{Het risico van willekeur}

Een volgend bezwaar is het risico van willekeur. In het strafrecht verwezenlijkt dat risico zich vooral aan de zijde van de

152. V.C. Geeraets, Restoratieve ficties, RMThemis 2014, afl. 2, p. 72-79.

153. Cleven, Lens \& Pemberton 2016, p. 7.

154. G. Mannozzi, Mediating conflicts in the medical sector. General considerations from the Italian perspective, Global Jurist (15) 2015, afl. 3, p. 291-327, op p. 304-306.

155. Braithwaite, J. (2006). Accountability and responsibility through restorative justice, in: M.W. Dowdle (red.), Public accountability: Designs, dilemmas and experiences, Cambridge: Cambridge University Press 2006, p. 33-51.

156. J. Braithwaite, Principles of restorative justice, in: A. von Hirsch, J.V. Roberts, A.E. Bottoms, K. Roach \& M. Schiff (red.), Restorative justice and criminal justice. Competing or reconcilable paradigms, Oxford/ Portland, OR: Hart Publishing 2003, p. 11.

157. B. van Stokkom, De gunfactor van herstelrecht: clementie, compassie en de zorg om de dader, TvH 2018, afl. 3, p. 33-49, op p. 46. schadeveroorzaker: wanneer daders en slachtoffers zelf inspraak hebben in de consequenties van een strafbaar feit, heeft dat gevolgen voor rechtszekerheid en rechtsgelijkheid. ${ }^{158}$ Dat is een gerechtvaardigd bezwaar, voor zover men aan die begrippen een doorslaggevende waarde hecht. Van Stokkom heeft daarop een andere visie. Hij bespreekt eerst welke behoeften slachtoffers hebben behalve materiële compensatie - wat, zoals wij ook reeds hebben gezien (par. 6.2), voor veel slachtoffers niet vooropstaat. Immateriële behoeften, zoals belang van erkenning, de wens dat de dader inziet dat hij fout zat, waardeherstel en rehabilitatie van de dader, brengen mee dat 'recht doen' voor veel slachtoffers iets anders betekent dan dat de dader zijn of haar 'verdiende loon' krijgt:

'Die retoriek gaat er geheel aan voorbij dat rechtvaardigheid niet kan worden gereduceerd tot de verdiende proportionele straf alleen. Alle aspecten van "verdiend zijn" moeten worden meegewogen, ook aspecten die samenhangen met de specifieke situatie waarin de dader verkeert en zijn morele responsiviteit: verdiende matiging van straf, verdiende hulp, verdiend ontzien worden, enzovoort. ${ }^{\text {'59 }}$

Willekeur kan ook een gevaar zijn omdat patiënten juist niet krijgen wat zij wél verdienen. Daarom hebben advocaten ook in het herstelrecht nog steeds een belangrijke rol, al is dat een andere dan die van 'zealous lawyer': Blad ziet (strafrecht)advocaten als mogelijke herstelgerichte coaches (niet te verwarren met de eerder besproken herstelcoaches). ${ }^{160}$ De professionele partijdigheid van advocaten betekent dat advocaten die bij de afwikkeling van de schade betrokken zijn niet verplicht kunnen worden een herstelgericht traject te volgen wanneer zij dat niet in het belang van hun cliënt achten - dat verdraagt zich overigens ook niet met het participatieve en vrijwillige karakter van herstelrecht -, maar zij kunnen hun cliënt wel alle opties voorleggen. $\mathrm{Zij}$ kunnen een belangrijke rol spelen in verwijzing naar herstelgerichte mogelijkheden en hun cliënt stimuleren het 'moreel juiste te doen'. ${ }^{161}$ Op procedureel vlak kunnen zij voorlichting geven over de aard en gevolgen van een herstelgerichte benadering en de rechten van partijen blijven bewaken. Voorlichting kan met name belangrijk zijn voor het waarborgen van informed consent met de procedure en de uitkomst.

\subsection{Complexe zaken}

Waarborging van procedurele rechten vangt mogelijk niet alle risico's van een herstelgerichte aanpak op. Buruma heeft twijfels bij herstelrecht omdat 'het slachtoffer niet de enige

158. In die zin bijv. Buruma 2004a, p. 163-164.

159. Van Stokkum 2018, p. 46.

160. Blad 2016, p. 18 en 24-25.

161. In onderzoek naar schadeafwikkeling in Nieuw-Zeeland zijn positieve ervaringen met advocaten neergetekend, zie Moore \& Mello 2017. Ook een recente uitgave van het tijdschrift Nederlandse Mediation besteedt aandacht aan de gunstige rol die advocaten kunnen spelen, bijv. door het temperen van onrealistische verwachtingen, zie NM 2019, afl. 2. 
eigenaar van het leed (is)'. ${ }^{162}$ Bij het plegen van een strafbaar feit worden niet alleen de rechten van het directe slachtoffer geschonden - Buruma schrijft in de context van het strafrecht -, maar zijn ook publieke belangen in het geding, zoals het belang bij een veilige samenleving en het onderhouden van wetten en waarden in de samenleving. Deze zorg wordt pregnanter naarmate de schade groter is. Buruma miskent, als ik hem goed lees, dat juist herstelrecht een uitgesproken publieke dimensie heeft, die zich sterker doet gelden naarmate de gemeenschap zwaarder getroffen is. ${ }^{163}$ Het is wat dat betreft wellicht behulpzaam om nog eens kort stil te staan bij wat men in het kader van herstelrecht met 'gemeenschap' bedoelt. Zehr maakt onderscheid tussen 'gemeenschap' en 'de samenleving. Wanneer de gevolgen van een schadeveroorzakende gebeurtenis 'de samenleving' aangaan - zoals een veilige samenleving, mensenrechten, welzijn van burgers -, kan volgens Zehr bepleit worden dat de reactie daarop in toenemende mate de overheid toekomt. ${ }^{164}$

Hier kan een parallel worden getrokken met de discussie die is ontstaan over tuchtklachten op basis van calamiteitenmeldingen bij de Inspectie Gezondheidszorg en Jeugd (IGJ). Er is wel voor gepleit om ook de melding van calamiteiten 'veilig' te maken, in die zin dat daaruit geen disciplinaire maatregelen kunnen volgen. ${ }^{165}$ Legemaate is van mening dat een dergelijke regeling de balans tussen bescherming en externe verantwoording te veel zou verstoren: 'Dat kan ertoe leiden dat het publieke vertrouwen in de kwaliteitssystemen van de gezondheidszorg nog meer onder druk komt te staan dan nu al het geval is. ${ }^{166}$ Tegelijkertijd meent ook Legemaate dat optreden bij calamiteiten wel zo 'blame free' mogelijk moet gebeuren. ${ }^{167}$ Onttrekt een herstelgericht perspectief op schadeafwikkeling incidenten of mogelijke calamiteiten aan het zicht van kwaliteitsbevorderende activiteiten? Waarschijnlijk niet. In paragraaf 6.2 is beschreven hoe juridische procedures in de gezondheidszorg vaak verkokerd zijn. Dat betekent dat juist wanneer schade strikt juridisch wordt afgewikkeld, in dat proces geen of weinig aandacht wordt besteed aan kwaliteitsaspecten. In een herstelgerichte aanpak zal dat anders zijn: niet alleen is de kring van betrokkenen waarschijnlijk groter, ook is de blik op wat er nodig is om tot herstel te komen breder dan nu vaak het geval is. Kwaliteitsverbetering is voor zowel patiënten als zorg-

162. Buruma 2004a, p. 164 . Hier valt tegen in te brengen dat in het herstelrecht de publieke dimensie juist een uitgesproken dimensie heeft, omdat het idee is dat herstelrecht bijdraagt aan het voorkomen van recidive. Dat geldt waarschijnlijk meer voor herstelconferenties dan voor mediation of bemiddeling.

163. Dat kan komen doordat hij herstelrecht niet nauwkeurig definieert, maar daaronder allerlei werkwijzen verstaat die niet punitief zijn. Y. Buruma, Doubts on the upsurge of the victim's role in criminal law, in H. Kaptein \& M. Malsch (red.), Crime, victims and justice. Essays on principles and practice, Hampshire: Ashgate 2004, p. 1-15, op p. 2.

164. Zehr 2015, p. 38.

165. I. Meynaar, I. Purmer, Ph. Kahn \& Th. van Woerkom, Melder calamiteit verdient bescherming: dreiging van tuchtzaak strijdig met veilige meldcultuur, Medisch Contact 2018, afl. 5, p. 2.

166. J. Legemaate, Rechtstekorten in het gezondheidsrecht, TvGR 2018, p. 193-203, op p. 198.

167. Legemaate 2017 , p. 2 verleners een belangrijke stap om te kunnen accepteren wat er is gebeurd. In het gezondheidsrecht kan een herstelgericht perspectief hier dus juist van toegevoegde waarde zijn.

\subsection{Herstelgerichte professionals}

Herstelrecht noopt tot een herijking van de manier waarop juristen worden opgeleid. Op de rechtenfaculteit van de Vrije Universiteit wordt daar volop aan gewerkt. Die aandacht is zichtbaar in het aanbod van de afstudeerrichting Conflicthantering, rechtspraak en mediation (CRM), ${ }^{168}$ die veel studenten combineren met een van de meer 'juridisch' ingestoken afstudeerrichtingen. Voor studenten die dat wat al te veel van het goede vinden, wordt (min of meer) dezelfde materie ook als keuzevak aangeboden. ${ }^{169}$ Maar ook in de klassieke juridische vakken, zoals het aansprakelijkheidsrecht, wordt stilgestaan bij de ongewenste effecten die het aansprakelijkheidsrecht kan hebben op hen die daarmee te maken krijgen. Dat is echter voor veel studenten nog maar theorie. Voor veel van hen zal onduidelijk zijn hoe zij de aangeboden materie in de praktijk kunnen toepassen, als ze het tegen die tijd niet al lang en breed zijn vergeten. Ligt hier een taak weggelegd voor de beroepsopleidingen?

It takes two to tango - een herstelgerichte juridische aanpak heeft waarschijnlijk weinig kans van slagen wanneer de betrokken zorgverlener en/of zorgaanbieder niet aan boord zijn. Openheid mag inmiddels als norm zijn aanvaard, dat betekent niet dat het geven van openheid als vanzelfsprekend goed verloopt. Uit de praktijk van Leernetwerk OPEN weten wij dat openheid nadrukkelijk moet worden georganiseerd. Eén aandachtspunt waaromtrent beleid zou moeten bestaan, is de ondersteuning van zorgverleners bij gesprekken met patiënten waarbij er iets is misgegaan. Dat geldt niet alleen voor de manier waarop wordt gecommuniceerd, maar ook waarover: zo bestaan er nog veel misverstanden over het verschil tussen het aanbieden van excuses en het erkennen van aansprakelijkheid. ${ }^{170}$ Goede voorlichting, ${ }^{171}$ communicatietrainingen ${ }^{172}$ en coaching bij gesprekken met patiënten zijn manieren om daaraan tegemoet te komen. ${ }^{173}$

168. Zie https://masters.vu.nl/en/programmes/rechtsgeleerdheid-conflict hantering-rechtspraak-mediation/index.aspx.

169. Zie www.vu.nl/nl/studiegids/2018-2019/master/m-o/notarieel-recht/ index.aspx?view $=$ module\&origin $=50056717 \& \mathrm{id}=51104486$.

170. A.M. Zwart Hink, Moet wie excuses aanbiedt ook schade vergoeden? Mythe en werkelijkheid over het verband tussen excuses en aansprakelijkheid, NJB 2017/92, p. 2800-2808.

171. Zie bijv. S.E. McCarthy, C.A. O'Boyle \& A. O'Shaughnessy, Online patient safety education programme for junior doctors: Is it worthwhile? Irish Journal of Medical Science 2016/185, afl. 1, p. 51-58; S.D. Brown, M.J. Callahan, D.M. Browning e.a., Radiology trainees' comfort with difficult conversations and attitudes about error disclosure. Effect of a communication skills workshop, Journal of the American College of Radiology (11) 2014, afl. 8, p. 781-787.

172. Zie bijv. S. Sukalich, J.O. Elliot \& G. Ruffner, Teaching medical error disclosure to residents using patient-centered simulation training, Academic Medicine (89) 2014, afl. 1, p. 136-143.

173. J. Shapiro, L. Robins, P. Galowitz, T.H. Gallagher \& S. Bell, Disclosure coaching: An ask-tell-ask model to support clinicians in disclosure conversations, Journal of Patient Safety 2018 (online publicatie voor print). 


\section{Tot slot}

Herstelrecht als theoretisch kader kan helpen een antwoord te vinden op de vraag hoe je een claim 'just' kunt afwikkelen. Herstelrecht geeft concrete handvatten hoe de afwikkeling van claims op een herstellende en inclusieve manier kan worden opgepakt. Een restorative aanpak gaat daarbij uit van behoeften in plaats van rechten, en richt de blik op de toekomst in plaats van over de schouder.

Wanneer het gaat over de toepassing van herstelrecht in de gezondheidszorg is er maar weinig empirie om ons te helpen. De kennis die we wel hebben, is bemoedigend, maar niet zomaar te extrapoleren naar de afwikkeling van medische claims. Wanneer het gaat om de ervaringen van slachtoffers en daders wordt in de internationale literatuur de vergelijking gemaakt tussen een herstelrechtproces en criminal court litigation, al wordt dit niet altijd geëxpliciteerd en wordt soms simpelweg gesproken van 'traditional legal system'. De verschillen tussen een (common law-)strafproces en een Nederlandse claimprocedure zijn zó groot, dat die vergelijking al snel mank gaat. Maar ook wanneer het gaat om Nederlandstalige literatuur is een strafproces geen claimprocedure, en is een zorgverlener geen crimineel.

Kijken we echter met een restorative bril naar de behoeften van patiënten zoals we die uit onderzoek kennen, dan weten we wel dat patiënten de voorkeur geven aan informele klachtenprocedures boven formele klachtenprocedures, dat patiënten vaak juridische stappen ondernemen omdat zij informatie willen, erkenning, excuses of medeleven van de zorgverlener, en dat zij met hun klacht of claim willen voorkomen dat een ander hetzelfde overkomt. Bezien we de zorgverlener vanuit hetzelfde perspectief, dan is bekend dat zorgverleners gebaat zijn bij opvang en begeleiding om goed met patiënten in gesprek te gaan, en dat goede begeleiding kan bijdragen aan posttraumatische groei, in die zin dat zij betere zorgverleners worden door wat zij hebben meegemaakt. Al kunnen we vanuit de empirie dus nog geen harde conclusies trekken, vanuit de theorie heeft een door herstelrecht geïnspireerde aanpak aan patiënten en zorgverleners veel te bieden.

Eerder is de benodigde cultuuromslag beschreven als een paradigmaverschuiving, maar mogelijk hoeft de revolutie niet ingrijpend te zijn. Er zijn binnen de huidige rechtspraktijk aanknopingspunten om herstelrecht te faciliteren. Daarvoor zal echter wel meer moeten worden samengewerkt dan nu de praktijk is, en dat wordt nog wel spannend. Want de samenwerking die daarvoor nodig is, beperkt zich niet tot de verantwoordelijke functionarissen in de gezondheidszorg, maar moet ook worden gerealiseerd tussen de medische en juridische discipline, en tussen belangenbehartigers en verzekeraars - een relatie die zich tot dusver niet karakteriseerde door een overmaat aan wederzijdse affectie. Het komt erop aan of men het gezamenlijk belang inziet bij een informele, herstelgerichte aanpak van claims wanneer dat kan, met de mogelijkheid om alle andere middelen uit de kast te trekken wanneer dat nodig is. Voor zorgaanbieders, zorgverleners en patiënten die betrokken zijn bij een klacht of claim ligt dat belang in het voorkomen van procedurele schade en de bevordering van de kwaliteit van zorg. 